\begin{tabular}{|c|l|}
\hline Title & Cyclic deformation of granular material subjected to moving-wheel loads \\
\hline Author(s) & Ishikawa, Tatsuya; Sekine, Etsuo; Miura, Seiichi \\
\hline Citation & $\begin{array}{l}\text { Canadian Geotechnical Journal, 48(5), 691-703 } \\
\text { https://doi.org/40.1139/10-099 }\end{array}$ \\
\hline Issue Date & 2011-05 \\
\hline Doc URL & http://hdl.handle.net/2115/46206 \\
\hline Type & article(author version) \\
\hline File Information & CGJ48-5_691-703.pdf \\
\hline
\end{tabular}

Instructions for use 


\title{
CYCLIC DEFORMATION OF GRANULAR MATERIAL SUBJECTED TO MOVING WHEEL LOADS
}

\author{
Tatsuya Ishikawa $^{\text {i) }}$, Etsuo Sekine ${ }^{\text {ii) }}$ and Seiichi Miura ${ }^{\text {iii) }}$
}

\section{Corresponding author:}

${ }^{i)}$ Tatsuya Ishikawa, Dr.Eng., Associate Professor

Laboratory of Analytical Geomechanics, Graduate School of Engineering, Hokkaido University

Kita 13, Nishi 8, Kita-ku, Sapporo, 060-8628, Japan

TEL \& FAX: +81-11-706-6202

E-mail: t-ishika@eng.hokudai.ac.jp

\section{Co-authors:}

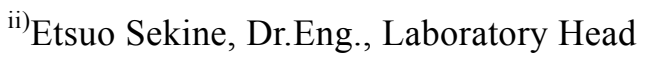

Track Structures \& Geotechnology, Track Technology Division, Railway Technical Research Institute

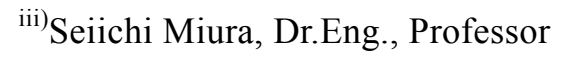

Laboratory of Analytical Geomechanics, Graduate School of Engineering, Hokkaido University 


\begin{abstract}
This paper describes a new testing method to examine the mechanical behavior of railroad ballast subjected to repeated train passages on ballasted track. Two types of cyclic loading test, namely a single-point loading test and a moving-wheel loading test, were performed with small-scale models of ballasted track. Next, a "multi-ring shear apparatus" was developed as a type of torsional simple shear apparatus, and the applicability of a newly proposed multi-ring shear test to an element test of railroad ballast subjected to moving-wheel loads was examined by comparing the results of multi-ring shear tests with those of small-scale model tests. As a result, it was recognized that cumulative strain obtained from multi-ring shear tests is almost equivalent to the one derived from small scale-model tests. Moreover, it was revealed that the difference between loading methods has a considerable influence on the cyclic plastic deformation of railroad ballast because settlement in a moving-wheel loading test was much larger than the one in a single-point loading test. These results lead to the conclusion that a multi-ring shear test has an excellent applicability to the estimation of deformation behavior of granular materials subjected to movingwheel loads.
\end{abstract}

Key words: base course, cyclic load, gravel, railoroad, special shear test 


\section{INTRODUCTION}

The study of "track deterioration" is one of the principal assignments in railway engineering because track deterioration has serious consequences on the safety of train operations (Selig and Waters 1994). Track deterioration observed mainly at ballasted tracks as shown in Figure 1 is a phenomenon where the rail level at a train passage gradually becomes irregular toward the longitudinal direction of railway track with repeated train passages. In general, a dominant factor of track deterioration at ballasted tracks is typically uneven subsidence of railroad ballast, a pile of well-compacted crushed stones, caused by train loads. Therefore, it is necessary for the rationalization of a present design method for ballasted track and the reduction of maintenance costs to elucidate the cumulative irreversible (plastic) deformation characteristics of railroad ballast subjected to cyclic moving wheel-loads in detail.

The mechanism of track deterioration is being researched in many countries. Nevertheless, a number of uncertainties about the mechanism of track deterioration still remain. One of the reasons for this seems to lie in the loading methods of conventional model tests and laboratory element tests. So far, a variety of loading tests with model track and model ballast have been performed by many researchers (Raymond and Bathurst 1987, Ishikawa and Namura 1995, Anderson and Key 2000, Hwang et al. 2001). However, most of these tests are single-point loading tests, in which pulsating compression loads were repeatedly applied to a point of model track. Moreover, though cyclic triaxial compression tests with constant amplitude of deviator stress while keeping confining pressure constant have been performed as an element test to examine the behavior of railroad ballast subjected to moving-wheel loads (Raymond and Davies 1978, Ishikawa et al. 1997, Indraratna et al. 1998, Kohata et al. 1999, Suiker et al. 2005, Lackenby et al. 2007), the loads merely increased and decreased, and the loading direction never changed throughout the test. In contrast, it is said that the principal stress axes rotate inside substructures like railroad ballast and roadbed as vehicles approach and pass a given location on 
the rail and road (Chan and Brown 1994, Burrow et al. 2005, Momoya et al. 2005, Powrie et al. 2008). Therefore, it seems that the above-mentioned conventional loading tests are not appropriate for simulating the actual stress states inside substructures under moving-wheel loads.

Brown (1996) suggested the importance of principal stress axis rotation on the performance of pavement and railway track. More recently, as a model test in consideration of the effect of moving-wheel loads on cyclic plastic deformation of roadbed and railroad ballast, moving-wheel loading tests, in which a wheel with constant vertical load travels cyclically along rails as in actual train loading, were conducted by Hirakawa et al. (2002) and Momoya et al. (2005). These investigations showed that the behavior of substructures in moving-wheel loading tests differs from that in single-point loading tests. Powrie et al. (2007) reported theoretical stress paths experienced by a ballast element during train passage in terms of principal stress axis rotation. Moreover, Wong and Arthur (1985), Towhata et al. (1994), Gräbe (2002), Momoya et al. (2007), and Gräbe and Clayton (2009), who examined the mechanical behavior of various granular materials subjected to moving-wheel loads, demonstrated that the rotation of principal stress axes has a strong influence on deformation-strength characteristics. However, the development of a testing method that is easy to use has been expected in order to apply a laboratory element test for evaluating the effect of moving-wheel loads to practical situations. With this being the case, this paper newly introduces a simple testing method to examine the mechanical behavior of railroad ballast subjected to cyclic moving-wheel loads in terms of the strength and deformation characteristics of coarse granular materials.

To begin, in this research two types of small-scale model tests that differ in loading method, namely single-point loading tests and moving-wheel loading tests, are performed and the effects of moving-wheel loads on cyclic plastic deformation of railroad ballast are examined by comparing both test results. Next, a multi-ring shear apparatus, which can evaluate the effect of rotating principal stress axes under shearing on the deformation-strength characteristics of 
granular materials, is experimentally developed as a type of torsional simple shear apparatus, and the performance is evaluated by comparing the test results with those of hollow cylinder torsional shear tests. Finally, two types of multi-ring shear tests, which correspond to the above-mentioned small-scale model tests, are performed. The validity of new testing methods with the multi-ring shear apparatus for a laboratory element test of railroad ballast subjected to moving-wheel loads is examined by comparing the test results with those of small-scale model tests in terms of the effects of the rotation of principal stress axes on cyclic plastic deformation of railroad ballast.

\section{MODEL TEST OF BALLASTED TRACK}

\section{Test materials}

Two types of test samples of differing mean grain sizes were employed in this investigation. The gradation curves for the test samples are shown in Figure 2, together with their mean grain sizes $\left(D_{50}\right)$, uniformity coefficients $\left(U_{\mathrm{c}}\right)$, minimum dry density $\left(\rho_{\mathrm{dmin}}\right)$, and maximum dry density $\left(\rho_{\mathrm{dmax}}\right)$. Railroad "ballast" in Japan is usually composed of angular, crushed, hard andesite stone. Proper grading of railroad ballast provided by the Japanese railway specification has a grain size distribution ranging from $10 \mathrm{~mm}$ to $60 \mathrm{~mm}$ (Ohshima 1990). Both test samples in this paper have one-fifth the mean grain size of the original ballast and a grain-size distribution similar to the above-mentioned proper grading of railroad ballast (Figure 2). The term " $1 / 5 \mathrm{~A}$ ballast" is used to refer to the model ballast that has a smaller uniformity coefficient, and the term " $1 / 5 \mathrm{~B}$ ballast" is used to refer to the other. The specimens of model ballast were kept under air-dried conditions throughout all tests.

Model ballast was placed to a depth exceeding $50 \mathrm{~mm}$ in a rigid soil container, $2.0 \mathrm{~m}$ wide, $0.3 \mathrm{~m}$ deep, and $0.4 \mathrm{~m}$ high. This ballast was compacted repeatedly with a loaded plate at a pressure of approximately $100 \mathrm{kPa}$ per unit area until the dry density of the railroad ballast reached over $85 \%$ of the maximum dry density $\left(\rho_{\mathrm{dmax}}\right)$ as shown in Figure 2 (i.e., dry density $\rho_{\mathrm{d}}=$ 
$1.43 \mathrm{~g} / \mathrm{cm}^{3}$ for $1 / 5 \mathrm{~A}$ ballast and $\rho_{\mathrm{d}}=1.48 \mathrm{~g} / \mathrm{cm}^{3}$ for $1 / 5 \mathrm{~B}$ ballast). A rigid steel plate was selected for the roadbed of the model track to prevent penetration of the ballast particles into the roadbed and to regard model ballasted track as a single-layer structure for simplification of the experimental condition. To increase the surface roughness between the railroad ballast and roadbed, No. 120 sandpapers were glued on the roadbed surface. Moreover, a friction-reduction layer (Tatsuoka et al. 1991) composed of silicone grease and a rubber membrane were inserted between an acrylic side panel of the soil container and the railroad ballast.

\section{Moving-wheel loading test}

The general test arrangement of a moving-wheel loading test is shown in Figure 3. The model track, which simulates a longitudinal section of ballasted track, is in the plane strain state with the section assumed to continue infinitely. It is a one-fifth scale model of a full-scale track employed normally in Japanese railway systems. Track components of the model track are two steel rails, 15 aluminum sleepers, railroad ballast made of model ballast, and steel roadbed. To roughly measure the rail seat force, a two-component loadcell (Tatsuoka 1988), which could measure both normal and shear components of the rail seat force was installed between the rail seats and sleepers as shown in Figure 3. As well, a displacement transducer located above each sleeper was employed to measure vertical displacement of a sleeper under cyclic loading.

Cyclic loading was performed by a loading wheel as follows. Figure 4 shows the loading pattern of vertical loads in a moving-wheel loading test. A wheel with a prescribed vertical load $(P)$ of $4.0 \mathrm{kN}$ travels along the rails at a constant speed of $700 \mathrm{~mm} / \mathrm{min}$ and makes 100 round trips between two ends of the rails cyclically to simulate actual train loading. The vertical load $(P)$ of $4.0 \mathrm{kN}$ was selected in order to simulate a wheel load of about $70 \mathrm{kN}$ applied to actual ballasted track in consideration of the difference in area of the base between the model sleeper and the prototype. The running speed of the loading wheel adopted for this test was much lower than the 
actual train speed due to hardware constraints. It is documented that the magnitude of permanent settlement generated in ballasted tracks is not sensitive to the loading frequency in cases where the frequency is low (Eisenmann et al. 1993).

\section{Single-point loading test}

The general test arrangement of a single-point loading test is shown in Figure 5. The model track is a one-fifth scale model in the plane strain state like in the moving-wheel loading tests. However, it is composed of a single aluminum sleeper without rails, railroad ballast and steel roadbed. Pulsating compression vertical loads $\left(P_{\mathrm{r}}\right)$ ranging from 0.2 to $2.0 \mathrm{kN}$ were cyclically applied to the sleeper so that the maximum applied vertical load was almost equivalent to the maximum rail seat force measured at the No. 8 sleeper in the moving-wheel loading tests (Figure 3). A sinusoidal loading waveform was employed because this waveform is said to approximate the loading pulse applied to sleepers under actual field conditions (Raymond and Bathurst, 1987). The loading number was 200 cycles, and the loading frequency of $0.008 \mathrm{~Hz}$ was selected in consideration of the running speed of a loading wheel in moving-wheel loading tests.

\section{MULTI-RING SHEAR TEST OF BALLAST}

Test implementation

Figure 6 shows the schematic diagram of the multi-ring shear apparatus, which is similar to the multiple layered rings employed in liquefaction test of sand by Tanaka et al. (2001). The multiring shear apparatus is composed of a bottom plate, a loading plate, and rigid rings. Torsion (torque) can be loaded to a specimen, which is confined with a bottom plate, a loading plate, inside rings, and outside rings, by a direct drive motor (DDM) for torque loading installed on the bottom plate while the loading plate is held fixed. In addition, vertical loads can be applied to a specimen by a DDM for vertical loading mounted on the loading plate. To decrease the friction 
between a specimen and the rings as much as possible, the structure of the inside and outside rings is designed as if each ring can move freely throughout the loading. The width of a specimen is $60 \mathrm{~mm}$ (120 mm inside diameter, $240 \mathrm{~mm}$ outside diameter), and the height is changeable within the range 40 to $100 \mathrm{~mm}$ by changing the number of rings whose height is $20 \mathrm{~mm}$. In this paper, the height of the specimen was set equal to $60 \mathrm{~mm}$ in order to compare the experimental results obtained from multi-ring shear tests with those of the above-mentioned model tests.

The terms regarding size $(H, W, \phi)$, load, stress $(\sigma, \tau)$, and strain $(\varepsilon, \gamma)$ used in the multiring shear test as well as the coordinate system used $(a, r, \theta)$ are defined as shown in Figure 7. The axial stress $\left(\sigma_{\mathrm{a}}\right)$ was measured with a loadcell mounted on the loading plate, and the axial strain $\left(\varepsilon_{\mathrm{a}}\right)$ was measured with an external displacement transducer (Dial gauge). The shear strain $\left(\gamma_{\mathrm{a} \theta}\right)$ was calculated from the rotation angle of the DDM for torque loading and vertical displacement of the dial gauge. In the case of monotonic loading tests, the shear stress $\left(\tau_{\mathrm{a} \theta}\right)$ was measured with a torque transducer installed under the bottom plate and a load cell mounted on the loading plate, whereas in the case of cyclic loading tests, it was measured mainly with the torque transducer. Note that the lateral pressure $\left(\sigma_{\mathrm{r}}\right)$ could not be measured in this study. This is because the measured value of $\sigma_{\mathrm{r}}$ with four small pressure gauges installed in the inside and outside rings varied widely due to the point contact between ballast particles and pressure sensors, thereby leading to our judgment that the measuring method had a problem with respect to measurement precision.

\section{Test procedures and test materials}

A series of monotonic loading and cyclic loading multi-ring shear tests were individually performed for the same two types of test samples as the model tests in order to examine their deformation-strength characteristics. Specimens were prepared by tamping every $20 \mathrm{~mm}$ thick layer with a wooden rammer so as to approach the density of railroad ballast in the above- 
mentioned model tests, and they were kept under air-dried conditions throughout all multi-ring shear tests. Table 1 summarizes the initial dry densities $\left(\rho_{\mathrm{d} 0}\right)$ for all experiments performed in this paper. Note that according to the particle-size analysis performed after the multi-ring shear tests, particle breakage could hardly be discerned for both types of model ballast.

The loading process was performed as follows. In monotonic loading tests, after consolidating a specimen of model ballast one-dimensionally under a specified axial stress $\left(\sigma_{\mathrm{a}}\right)$, the shear stress $\left(\tau_{\mathrm{a} \theta}\right)$ was applied at a constant shear strain rate of $0.01 \% / \mathrm{min}$ while keeping $\sigma_{\mathrm{a}}$ constant. In cyclic loading tests, two types of loading mode were adopted to evaluate the effect of principal stress axis rotation on cyclic deformation of the ballast. One is the multi-ring shear test that uses a moving-wheel loading mode (ML-multi-ring shear test), in which after onedimensional consolidation, both shear stress $\left(\tau_{\mathrm{a} \theta}\right)$ and axial stress $\left(\sigma_{\mathrm{a}}\right)$ in sinusoidal waveforms as shown in Figure 8 are cyclically applied to the specimen. The other is the multi-ring shear test using a single-point loading mode (FL-multi-ring shear test), in which after the consolidation, only axial stress $\left(\sigma_{\mathrm{a}}\right)$ in a sinusoidal waveform is cyclically applied to the specimen. Accordingly, the ML-multi-ring shear test simulates the moving-wheel loading test, and the FL-multi-ring shear test simulates the single-point loading test. In both multi-ring shear tests, the number of loading cycles $\left(N_{\mathrm{c}}\right)$ was 200 , and the loading frequency $(f)$ of $0.008 \mathrm{~Hz}$ was selected by referring to the experimental conditions of the small-scale model tests. Note that the waveforms of $\tau_{\mathrm{a} \theta}$ and $\sigma_{\mathrm{a}}$ are the imitation of normal and shear components, respectively, of the rail seat force measured in the above-mentioned moving-wheel loading test by the two-component load cell, although for detailed evaluation of the effect of principal stress axis rotation the amplitudes of $\tau_{\mathrm{a} \theta}$ and $\sigma_{\mathrm{a}}$ are altered in ML-multi-ring shear tests assuming that the wheel load $(P)$ changes. The waveforms of $\tau_{\mathrm{a} \theta}$ and $\sigma_{\mathrm{a}}$ employed in ML-multi-ring shear tests are in good agreement with those presented in the conventional research (Brown 1996, Powrie et al. 2007). 


\section{BEHAVIOR OF MODEL BALLASTED TRACK UNDER CYCLIC LOADING}

\section{Behavior during moving-wheel loading test}

Figure 9 shows a typical relationship of $1 / 5 \mathrm{~B}$ ballast between the rail seat forces at the No. 8 sleeper and the position of a loading wheel. The arrow in the figure designates the direction of movement of the loading wheel. Figure 9 shows how a wheel load acts on a single sleeper in the moving-wheel loading test. The normal component of the rail seat force $\left(P_{\mathrm{r}}\right)$ gradually rises from zero as a loading wheel approaches the No. 8 sleeper, and it reaches the peak, which is approximately $50 \%$ of the designated wheel load $(P)$, just on the No. 8 sleeper. After the peak, there is a decrease in the rail seat force and it returns to zero at the opposite rail end. Meanwhile, the relation of the shear component $\left(Q_{\mathrm{r}}\right)$ is different from that of the normal component. The major differences between both components generated during the moving-wheel loading test are the sign of the rail seat force and the wheel position where they reach the peak. For example, the normal component has the peak just on the No. 8 sleeper, while the shear component is equal to zero at the same position. The normal component remains the compression side through loading, although the shear component changes its sign according to the position of the loading wheel. However, both relations between the rail seat force and the wheel position are symmetric with respect to the position of the No. 8 sleeper. These results indicate that the principal stress axes rotate inside the railroad ballast as a loading wheel approaches and passes a given location on the rail. Incidentally, although Figure 9 shows the relationships in the case of movement of a loading wheel toward the right, it was found that the relationships in the case of movement toward the left approximately coincided in shape and sign with those in Figure 9.

Figure 10 shows the load-displacement relations of the No. 8 sleeper as shown in Figure 3 for both types of model ballast. At the early stages of cyclic loading, a large hysteresis loop is described by a loading curve and an unloading curve, and the permanent settlement increases greatly. However, with the increment of loading cycles, the area of the hysteresis loop decreases 
and the deformation characteristics of the railroad ballast become elastic and constant. Figure 11 shows the relations of the No. 8 sleeper between the vertical displacement $\left(u_{\max }\right)$ at the maximum vertical load during a loading cycle, the vertical displacement $\left(u_{\min }\right)$ at unloading, and the number of loading cycles $\left(N_{\mathrm{c}}\right)$ by comparing the curves of the $1 / 5 \mathrm{~A}$ ballast with those of $1 / 5 \mathrm{~B}$ ballast. Note that $u_{\min }$ represents the cumulative permanent settlement. Both $u_{\max }$ and $u_{\min }$ increase slowly with increasing $N_{\mathrm{c}}$ after the exponential increment at the early stages of cyclic loading, and their rates of increase decrease with the increment of $N_{\mathrm{c}}$. The displacement amplitude $\left(u_{\max }-u_{\min }\right)$ is almost constant even if the loading cycle increases, and the result indicates that the increase of $u_{\max }$ originates in the cumulative permanent settlement of the railroad ballast. Moreover, according to Figure 11, the permanent settlement of the $1 / 5 \mathrm{~A}$ ballast is more likely to increase with the repetition of loads than that of the $1 / 5 \mathrm{~B}$ ballast. This result indicates that a slight difference in the grain-size distribution of ballast noticeably influences the development of residual settlement under cyclic loading in moving-wheel loading tests.

\section{Behavior during single-point loading test}

Figure 12 shows the load-displacement relations of the sleeper as shown in Figure 5 for both types of model ballast. Although the results of single-point loading tests and the results of moving-wheel loading tests differ in that the amplitude of the vertical loads is constant in the single-point loading test, both test results resemble each other in the shape of hysteresis loop and the transition due to cyclic loading. Figure 13 shows the relations of the sleeper between $u_{\max }$, $u_{\min }$ and $N_{\mathrm{c}}$ by comparing the curves of the $1 / 5 \mathrm{~A}$ ballast with those of the $1 / 5 \mathrm{~B}$ ballast. The results of single-point loading tests are similar in the increasing tendencies of $u_{\max }$ and $u_{\min }$ with an increase in $N_{\mathrm{c}}$ to those of moving-wheel loading tests. Moreover, the permanent settlement of the $1 / 5 \mathrm{~A}$ ballast is larger than that of the 1/5B ballast in the same way as moving-wheel loading tests. However, the amount of accumulated permanent settlement caused by single-point loading is 
much smaller than the one caused by moving-wheel loading, and the difference between both types of model ballast cannot be discerned clearly.

\section{Effects of moving-wheel loads}

To evaluate the effects of the moving-wheel loads on cyclic plastic deformation of railroad ballast more quantitatively, the relation after the convergence of initial settlement between $u_{\max }$ and $N_{\mathrm{c}}$ was approximated by an equation of the first degree as shown in Figures 11 and 13. In this case, it is considered that the y-segment of the approximate linear equation represents the amount of initial settlement $(\alpha)$ and its slope represents the rate of progressive settlement $(\beta)$ after the convergence of initial settlement. Figure 14a shows the approximate values of $\alpha$ and $\beta$ in the test results for both types of model ballast obtained from moving-wheel loading tests and single-point loading tests. According to Figure 14a, although both $\alpha$ and $\beta$ of the 1/5A ballast are larger than those of the 1/5B ballast regardless of loading methods, both $\alpha$ and $\beta$ of single-point loading tests are much smaller than those of moving-wheel loading tests when the grain-size distributions are the same. This result indicates that the difference in loading methods has a considerable influence on the cyclic plastic deformation of railroad ballast. Therefore, in the case where a higher accuracy of prediction is required, it is necessary to improve the conventional testing methods for elucidating cyclic plastic deformation of railroad ballast, and for that reason the moving-wheel loading test seems to be effective as it can simulate the actual stress states of railroad ballast under train loads.

\section{PERFORMANCE EVALUATION OF MULTI-RING SHEAR APPARATUS}

The basic performance of a multi-ring shear apparatus is examined as a torsional simple shear apparatus of granular materials. Figure 15 shows how the specimen of glass beads (diameter $D=5$ $\mathrm{mm}$ ) confined by inside and outside rings deforms under torsional shearing. It can be observed 
that the horizontal displacement of colored glass beads line up vertically before shear increases linearly from the fixed loading plate to the rotated bottom plate. This indicates that a specimen subjected to torsional shear in the multi-ring shear test is in simple shear deformation. Figure 16 compares the relations for both test samples between two types of shear stress $\left(\tau_{\mathrm{a} \theta}\right)$, which were measured at the bottom plate and the loading plate, and shear strain $\left(\gamma_{\mathrm{a} \theta}\right)$ in monotonic loading multi-ring shear tests. For plots with the same strain levels, both shear stresses are nearly equal irrespective of test samples. This indicates that the torsion (torque) can be transferred from a lower part of a specimen to the upper part without any loss due to the friction between a specimen and rings in the multi-ring shear apparatus. Figure 17 shows the $\tau_{\mathrm{a} \theta}-\gamma_{\mathrm{a} \theta}$ relations of the glass beads in cyclic loading multi-ring shear tests. In reversing the direction of torsional shear, a hysteresis loop of the stress-strain relation is free of backlash and overshoot regardless of $N_{\mathrm{c}}$. This indicates that the control of a DDM for torque loading is hardly influenced by the inertia of the test apparatus. Furthermore, the fact that the hysteresis loop is approximately symmetric with respect to the origin of the coordinates shows that the friction is not changed by the direction of rotation. Consequently, it appears reasonable to conclude that the newly developed multi-ring shear apparatus is appropriate for a torsional simple shear apparatus of granular materials.

Next, the validity of experimental results obtained from multi-ring shear tests under monotonic loading conditions is examined as compared with those of hollow cylinder torsional shear tests performed under similar experimental conditions. In the hollow cylinder torsional shear tests, the size of the specimen was $20 \mathrm{~mm}$ in width $(60 \mathrm{~mm}$ inside diameter, $100 \mathrm{~mm}$ outside diameter) and $300 \mathrm{~mm}$ in height, and the effective confining pressure $\left(\sigma_{\mathrm{c}}{ }^{\prime}\right)$ was set to correspond to the axial stress $\left(\sigma_{\mathrm{a}}\right)$ of multi-ring shear tests. Figure 18 shows the $\tau_{\mathrm{a} \theta}-\gamma_{\mathrm{a} \theta}-\varepsilon_{\mathrm{a}}$ relations of various test samples in multi-ring shear tests, as compared with the relations in hollow cylinder torsional shear tests. It is recognized that the results of multi-ring shear tests are similar with respect to the shape of stress-strain relationships to those of hollow cylinder torsional shear tests, 
irrespective of the type test samples. Moreover, Figure 19 compares the relations of multi-ring shear tests between angle of shear resistance $\left(\phi_{\mathrm{a} \theta}\right)$ and $\sigma_{\mathrm{a}}$ with the relations of hollow cylinder torsional shear tests between $\phi_{\mathrm{a} \theta}$ and $\sigma_{\mathrm{c}}{ }^{\prime}$. $\phi_{\mathrm{a} \theta}$ values obtained from both tests increase in order of the glass beads, sand, and ballast regardless of testing methods although $\phi_{\mathrm{a} \theta}$ in the multi-ring shear test is smaller than $\phi_{a}$ in the hollow cylinder torsional shear test at the same stress level. These results indicate that the multi-ring shear test is valid as a torsional shear test of granular materials in consideration of the difference in the specimen size, the friction between a specimen and rings, and the lateral pressure between both testing methods. Therefore, it seems reasonable to conclude that the mechanical behavior of granular materials under torsional simple shearing can be evaluated with the multi-ring shear apparatus.

\section{BEHAVIOR OF BALLAST UNDER CYCLIC LOADING}

\section{Cyclic deformation characteristics of ballast}

Figures $20 \mathrm{a}$ and $20 \mathrm{~b}$ show the relations of $1 / 5 \mathrm{~A}$ ballast between $\sigma_{\mathrm{a}}$ and the vertical displacement, $u$, obtained from an ML-multi-ring shear test and an FL-multi-ring shear test, respectively. Replacing experimental conditions of a moving-wheel loading test for model ballasted track with those of an ML-multi-ring shear test, the maximum axial stress $\left(\sigma_{\mathrm{a}}\right)_{\max }$ may represent the maximum loading state where a wheel is just above the sleeper, and the minimum axial stress $\left(\sigma_{\mathrm{a}}\right)_{\min }$ may represent the unloading state where a wheel is far beyond the sleeper. Figures $21 \mathrm{a}$ and $21 \mathrm{~b}$ shows the relations for both test samples between the vertical displacement $\left(u_{\max }\right)$ at $\left(\sigma_{\mathrm{a}}\right)_{\max }$, the vertical displacement $\left(u_{\min }\right)$ at unloading, and the number of loading cycles $\left(N_{\mathrm{c}}\right)$ obtained from an ML-multi-ring shear test and an FL-multi-ring shear test, respectively. Furthermore, Figure $14 \mathrm{~b}$ shows the approximate values of $\alpha$ and $\beta$ in the test results obtained from ML-multi-ring shear tests and FL-multi-ring shear tests for both types of model ballast.

From these figures, it is recognized that the cyclic plastic deformation obtained through 
the ML-multi-ring shear test is much larger than the one obtained through the FL-multi-ring shear test when other experimental conditions except the loading method are the same. Moreover, the difference between the results for two types of model ballast can hardly be distinguished in the FL-multi-ring shear test results, although the effect of grain-size distribution of the ballast on the development of residual settlement remarkably comes to the fore in the ML-multi-ring shear test results. These results indicate that the difference in loading methods --- that is, the difference whether the principal stress axes rotate or not --- has a significant influence on the cyclic plastic deformation of granular materials.

On the other hand, comparing Figure 20a with Figure 10 or Figure 20b with Figure 12, it is found that the load-displacement relationships of multi-ring shear tests closely resemble those of small-scale model tests irrespective of the loading mode. As well, according to Figure 14, the settlement characteristics obtained from multi-ring shear tests approximately coincide with those of small-scale model tests, regardless of loading methods and test samples. These results demonstrate that (i) the multi-ring shear apparatus has excellent applicability to the estimation of deformation behavior of granular materials subjected to repeated moving-wheel loads and (ii) the proposed load-controlling method --- which was employed in the multi-ring shear test using a moving loading mode --- in consideration of both the fluctuations in loads and the rotation of principal stress axes, can reproduce well the actual stress states inside railroad ballast under moving-wheel loads.

\section{Effects of principal stress axis rotation}

In general, the rotational angle of the principal stress axis $(\varphi)$ can be written using Equation 1, in the case of assuming that the major principal stress $\left(\sigma_{1}\right)$, the intermediate principal stress $\left(\sigma_{2}\right)$ and the minor principal stress $\left(\sigma_{3}\right)$ is given by Equation 2. Figure 22 illustrates the general stress conditions experienced on an element of railroad ballast under a moving-wheel load within the 
longitudinal plane.

$$
\begin{aligned}
& \varphi=\sin ^{-1} \sqrt{\frac{\sigma_{2}-\sigma_{3}}{\sigma_{1}-\sigma_{3}}} \\
& \sigma_{1}, \sigma_{3}=\frac{\sigma_{\mathrm{a}}+K_{0} \sigma_{\mathrm{a}}}{2} \pm \frac{\sqrt{\left(\sigma_{\mathrm{a}}-K_{0} \sigma_{\mathrm{a}}\right)^{2}+4 \tau_{\mathrm{a} \theta}{ }^{2}}}{2}, \sigma_{2}=\sigma_{\mathrm{r}}=K_{0} \sigma_{\mathrm{a}}
\end{aligned}
$$

$$
K_{0}=1-\sin \phi^{\prime}
$$

where $K_{0}$ is the coefficient of earth pressure at rest. Note that as the lateral pressure $\left(\sigma_{\mathrm{r}}\right)$ was not measured in this study, a $K_{0}$ of 0.28 was estimated by substituting the effective internal friction angle $\left(\phi^{\prime}\right)$ of $46.5^{\circ}$ into Jáky's formula (Equation 3). A $\phi^{\prime}$ of $46.5^{\circ}$ was derived from the results of medium-size triaxial compression tests on 1/5A ballast performed by Kohata and Miura (2004). Figure 23a shows an example of the change in the rotational angle of the principal stress axis during a loading cycle in the case of assuming that $K_{0}$ is a constant value of 0.30 . The principal stress axes rotate continuously during a loading cycle and the sign alternates from plus to minus at a half-period. Furthermore, the maximum rotational angle of the principal stress axis $(\varphi)_{\max }$ depends on the loading condition of the multi-ring shear tests. From Figure 23b, which compares the relations between $(\varphi)_{\max }$ and $\left(\tau_{\mathrm{a} \theta}\right)_{\max }$ under various $\left(\sigma_{\mathrm{a}}\right)_{\max }$ with the same assumption as in Figure 23a, it is observed that $(\varphi)_{\max }$ becomes large with the decrease in $\left(\sigma_{\mathrm{a}}\right)_{\max }$ when maintaining $\left(\tau_{\mathrm{a} \theta}\right)_{\max }$ constant or with the increase in $\left(\tau_{\mathrm{a} \theta}\right)_{\max }$ when maintaining $\left(\sigma_{\mathrm{a}}\right)_{\max }$ constant. Also, the $(\varphi)_{\max }-\left(\tau_{\mathrm{a} \theta}\right)_{\max }$ relations in the case of changing $K_{0}$ in the 0.2 to 0.4 range under a constant $\left(\sigma_{\mathrm{a}}\right)_{\max }$ are shown in Figure $23 \mathrm{c}$. Over the range of $K_{0}$, although $(\varphi)_{\max }$ increases slightly with the increase in $K_{0}$, the variation in $(\varphi)_{\max }$ is small as compared with the variation due to the difference in loading conditions.

To evaluate the effects of the principal stress axis rotation on cyclic plastic deformation of railroad ballast quantitatively, the ratio of axial strain in the ML-multi-ring shear test $\left(\varepsilon_{\mathrm{a}}{ }^{\mathrm{ML}}\right)$ to the one in the FL-multi-ring shear test $\left(\varepsilon_{\mathrm{a}}{ }^{\mathrm{FL}}\right)$, which is defined as "ratio of axial strain $\left(R_{\mathrm{S}}\right)$ " by Equation 4, is examined.

$$
R_{\mathrm{S}}=\frac{\varepsilon_{\mathrm{a}}^{\mathrm{ML}}}{\varepsilon_{\mathrm{a}}{ }^{\mathrm{FL}}}
$$


Figure 24 compares the relations between $R_{\mathrm{S}}$ and $N_{\mathrm{c}}$ of both test samples under various loading conditions. For both types of model ballast, $R_{\mathrm{S}}$ is approximately constant regardless of $N_{\mathrm{c}}$ although the magnitude depends on the loading condition and test sample. Accordingly, $\varepsilon_{\mathrm{a}}^{\mathrm{ML}}$ and $\varepsilon_{\mathrm{a}}^{\mathrm{FL}}$ are roughly related by a proportionality constant $R_{\mathrm{S}}$ throughout cyclic loading. This indicates that when experimental conditions except loading condition of shear stress are the same, the cumulative axial strain obtained from the ML-multi-ring shear test, in which the principal stress axes rotate during shear, can be estimated from the result of the FL-multi-ring shear test, in which the principal stress axes do not rotate throughout the test, by using $R_{\mathrm{S}}$.

$\mathrm{Yu}(2005)$ states that repeated loads in excess of the elastic shakedown limit will cause cyclic plastic deformation, and Brown et al. (2008) indicates that the shakedown condition is determined as a function of the applied shear to normal load ratio, the radius of the loaded area, and the strength parameters. Figure 25 shows the relations between the average ratio of axial strain $\left(R_{\mathrm{S}}\right)_{\text {ave }}$, which is the mean value of $R_{\mathrm{S}}$ for $N_{\mathrm{c}}=40$ and subsequent cycles, and $\left(\tau_{\mathrm{a} \theta}\right)_{\max }$ under various $\left(\sigma_{\mathrm{a}}\right)_{\max } .\left(R_{\mathrm{S}}\right)_{\text {ave }}$ increases with a decrease in $\left(\sigma_{\mathrm{a}}\right)_{\max }$ or with an increase in $\left(\tau_{\mathrm{a} \theta}\right)_{\max }$. Then, $\left(R_{\mathrm{S}}\right)_{\mathrm{ave}}$ is roughly approximated by Equation 5 , which regards $\left(\tau_{\mathrm{a} \theta}\right)_{\max }$ and $\left(\sigma_{\mathrm{a}}\right)_{\max }$ as explanatory variables.

$$
\left(R_{\mathrm{S}}\right)_{\mathrm{ave}}=\exp \left(a \frac{\left(\tau_{\mathrm{aa}}\right)_{\max }}{\left(\sigma_{\mathrm{a}}\right)_{\max }}\right)
$$

where $a$ is a constant depending on the test sample. The approximation results are represented by solid and dashed lines in Figure 25, and they agree well with the experimental results, regardless of loading conditions. These results have some commonalities with Yu (2005) and Brown et al. (2008). Moreover, from the comparison between Figures 23b and 25, it is recognized that a change in the average ratio of axial strain due to a change in loading condition is in good agreement with a change in the rotational angle of the principal stress axis. This indicates that the cumulative axial strain tends to increase with the increase in the rotational angle of the principal stress axis, and that the average ratio of axial strain is an index to evaluate the effect of the 
principal stress axis rotation on cumulative strain characteristic of railroad ballast subjected to moving-wheel loads. However, there is room for further investigation as to the validity of $K_{0}$ and $\varphi$ values.

\section{CONCLUSIONS}

The following summarizes the findings of this investigation:

Cumulative residual settlement of railroad ballast caused by single-point loading is much smaller than the one caused by moving-wheel loading, and the effect of grain-size distribution of ballast on the development of residual settlement can barely be evaluated precisely based on the results of single-point loading tests as compared with movingwheel loading tests. Accordingly, the difference in loading methods --- that is, the presence or absence of principal stress axis rotation --- has a considerable influence on cyclic plastic deformation of railroad ballast in small-scale model tests.

The control of a newly developed multi-ring shear apparatus, which is a torsional simple shear apparatus, is hardly influenced by the inertia of the apparatus and the friction between a specimen and the rings, and the results obtained from monotonic loading multi-ring shear tests are approximately similar in the stress-stain relationships and the angle of shear resistance to those of hollow cylinder torsional shear tests performed under similar experimental conditions for various granular materials.

Settlement characteristics obtained from cyclic loading multi-ring shear tests are almost equivalent to those in cyclic loading tests with small-scale model track, regardless of loading methods and test samples. Accordingly, the proposed load-controlling method in a multi-ring shear test using a moving-wheel loading mode seems to reproduce well the actual stress states under moving-wheel loads.

Cyclic plastic deformation in a multi-ring shear test using a moving-wheel loading mode 
(ML-multi-ring shear test), in which the principal stress axes rotate continuously during a loading cycle in the case where $K_{0}$ is assumed as a constant value, is much larger than the one in the multi-ring shear test using a single-point loading mode (FL-multi-ring shear test) when experimental conditions except loading condition of shear stress are the same. The cumulative axial strain in an ML-multi-ring shear test can be estimated from the one in the FL-multi-ring shear test by using the average ratio of axial strain between both tests, and the average ratio of axial strain can be estimated by the equation that regards shear stress and axial stress as an explanatory variable. Therefore, the cumulative axial strain tends to increase with the increase in the maximum rotational angle of the principal stress axis, which depends on the loading condition of multi-ring shear tests.

These findings lead to the conclusions that the multi-ring shear apparatus has excellent applicability to the estimation of deformation behavior of coarse granular materials subjected to repeated moving-wheel loads, and for that reason, the moving-wheel loading test seems to be appropriate for simulating the actual stress state inside railroad ballast at train passages. Furthermore, it appears reasonable to conclude that the average ratio of axial strain is an index to evaluate the effect of principal stress axis rotation on cumulative strain characteristic of railroad ballast subjected to moving-wheel loads. However, there is room for further investigation as to the validity of the estimated rotational angle of the principal stress axis and the applicability of the conclusions in this paper to other experimental conditions that differ with respect to types of granular material, track structure, loading condition, and so on.

\section{ACKNOWLEDGMENTS}

The authors would like to thank Mr. Keita Sugiyama, formerly at Hokkaido University, who performed laboratory shear tests and arranged the experimental results. This research was supported in part by Grant-in-Aid for Scientific Research (C) from Japan Society for the 
Promotion of Science (JSPS).

\section{REFERENCES}

Anderson, W.F., and Key, A.J. 2000. Model testing of two-layer railway track ballast. Journal of Geotechnical and Geoenvironmental Engineering, 126(4): 317-323.

Brown, S.F. 1996. Soil mechanics in pavement engineering. Géotechnique, 46(3): 383-426.

Brown, S.F., Juspi, S., and Yu, H.S. 2008. Experimental observations and theoretical predictions of shakedown in soils under wheel loading. In Advances in Transportation Geotechnics: Proceeding of the 1st International Conference on Transportation Geotechnics, Nottingham, UK, 25-27 August 2008. Edited by E. Ellis, H.S. Yu, G. McDowell, A. Dawson, and N. Thom. CRC Press, Taylor \& Francis Group, London, UK. pp.707-712.

Burrow, M.P.N., Ghataora, G.S., and Stirling, A.B.S. 2005. A rational approach to track substructure design. In Proceeding of Conference on Excellence in Railway Systems Engineering and Integration, Derby, UK, 25-26 November 2005.

Chan, F.W.K., and Brown, S.F. 1994. Significance of principal stress rotation in pavements. In Proceedings of the 13th International Conference on Soil Mechanics and Foundation Engineering, New Delhi, India, 5-10 January 1994. Taylor \& Francis, New York. pp.18231826.

Eisenmann, J., Leykauf, G., and Mattner, L. 1993. Deflection and settlement behavior of ballast. In Proceedings of the 5th International Conference on Heavy Haul Railway, Beijing, China, 6-11 June 1993. China Railway Society, China Academy of Railway Sciences, Beijing Railway Administration, and International Heavy Haul Association. pp.193-199.

Gräbe, P.J. 2002. Resilient and permanent deformation of railway foundations under principal stress rotation. Ph.D. Dissertation, University of Southampton, Southampton, UK.

Gräbe, P.J., and Clayton, C.R.I. 2009. Effects of principal stress rotation on permanent 
deformation in rail track foundations. Journal of Geotechnical and Geoenvironmental Engineering, 135(4): 555-565.

Hirakawa, D., Kawasaki, H., Tatsuoka, F., and Momoya, Y. 2002. Effects of loading conditions on the behaviour of railway track in the laboratory model tests. In Proceedings of the 6th International Conference on the Bearing Capacity of Roads, Railway and Airfields, Lisbon, Portugal, 24-26 June 2002. Edited by A.G. Correia and F.E.F. Branco. Swets \& Zeitlinger Publishers, Rotterdam, the Netherlands. pp.1295-1305.

Hwang, S.K., Lee, S.H., and Choi, C.Y. 2001. Performance of the reinforced railroad roadbed of crushed stones under the simulated cyclic loading using multi purpose loading system. In Proceedings of the World Congress in Railway Research (WCRR2001), Cologne, Germany, 25-29 November 2001. [CD-ROM].

Indraratna, B., Ionescu, D., and Christie, H.D. 1998. Shear behavior of railway ballast based on large-scale triaxial tests. Journal of Geotechnical and Geoenvironmental Engineering, 124(5): 439-449.

Ishikawa, T., and Namura, A. 1995. Cyclic deformation characteristics of railroad ballast in fullscale tests. Journal of Infrastructure planning and Management, 512/IV-27: 47-59. (in Japanese).

Ishikawa, T., Sunaga, M., Dong, J., and Namura, A. 1997. Cyclic deformation characteristics of railroad ballast in triaxial tests. Journal of Geotechnical Engineering, 575/III-42: 205-217. (in Japanese).

Kohata, Y., Jiang, G.L., and Sekine, E. 1999. Deformation characteristics of railroad ballast as observed in cyclic triaxial tests. In Poster Session Proceeding of the 11th Asian Regional Conference on Soil Mechanics and Geotechnical Engineering, Seoul, Korea, 16-20 August 1999. Edited by S.W. Hong, M.M. Kim, G.S. Yang, S.R. Lee, S.S. Chung, C.C. Ihm, H.T. Kim, J.B. Park, and B.S. Lee. A.A.Balkema, Rotterdam, the Netherlands. pp.21-22. 
Kohata, Y., and Miura, K. 2004. The effect of density and grain size distribution on the strength and deformation properties of the poorly-graded crushed gravels. In Proceeding of Hokkaido Branch of the Japanese Society of Civil Engineers, 60: pp.494-497. (in Japanese). Lackenby, J., Indraratna, B., McDowell, G., and Christie, D. 2007. Effect of confining pressure on ballast degradation and deformation under cyclic triaxial loading. Géotechnique, 57(6): $527-536$.

Momoya, Y., Sekine, E., and Tatsuoka, F. 2005. Deformation characteristics of railway roadbed and subgrade under moving-wheel load. Soils and Foundations, 45(4): 99-118.

Momoya, Y., Watanabe, K., Sekine, E., Tateyama, M., Shinoda, M., and Tatsuoka, F. 2007. Effects of continuous principal stress axis rotation on the deformation characteristics of sand under traffic loads. In Proceeding of the International Workshop on Design and Construction of Pavements and Rail Tracks -Geotechnical Aspects and Processed Materials-, Osaka, Japan, 13 September 2005. Edited by A.G. Correia, Y. Momoya, and F. Tatsuoka. Swets \& Zeitlinger Publishers, Rotterdam, the Netherlands. pp.77-87.

Ohshima, H., 1990. Rock quality tendencies and technical problems with JR railway ballast. Railway Technical Research Institute Report, 4(4): 18-26. [In Japanese.]

Powrie, W., Yang, L.A., and Clayton C.R.I. 2007. Stress changes in the ground below ballasted railway track during train passage. In Proceedings of the Institution of Mechanical Engineers, Part F: Journal of Rail and Rapid Transit, 221(2): 247-262.

Powrie, W., Priest, J.A., and Clayton, C.R.I. 2008. Recent research on railway track sub-base behaviour. In Advances in Transportation Geotechnics: Proceeding of the 1st International Conference on Transportation Geotechnics, Nottingham, UK, 25-27 August 2008. Edited by E. Ellis, H.S. Yu, G. McDowell, A. Dawson, and N. Thom. CRC Press, Taylor \& Francis Group, London, UK. pp. 37-46.

Raymond, G.P., and Bathurst, R.J. 1987. Performance of large-scale model single tie-ballast 
systems. Transportation Research Record, 1131: 7-14.

Raymond, G.P., and Davies, J.R. 1978. Triaxial tests on dolomite railroad ballast. Journal of Geotechnical Engineering Division, 104(6): 737-751.

Selig, E.T., and Waters, J.M. 1994. Track geotechnology and substructure management, Thomas Telford, London.

Suiker, A.S.J., Selig, E.T., and Frenkel, R. 2005. Static and cyclic triaxial testing of ballast and subballast. Journal of Geotechnical and Geoenvironmental Engineering, 131(6): 771-782.

Tanaka, K., Suemasa, N., and Katada, T. 2001. Liquefaction test of sand containing clay contents by using multiple layer rings. In Proceeding of the 36th Japan National Conference on Geotechnical Engineering, Tokushima, Japan, 12-14 June 2001. Japanese Geotechnical Society, Tokyo, Japan. pp.407-408. (in Japanese)

Tatsuoka, F. 1988. Some recent developments in triaxial testing system for cohesionless soils. In Advanced triaxial testing of soil and rock. STP 977. American Society for Testing and Materials, West Conshohocken, Pa. pp. 7-67.

Tatsuoka, F., Okahara, M., Tanaka, T., Tani, K., Morimoto, T., and Siddiquee, M.S.A. 1991. Progressive failure and particle size effect in bearing capacity of a footing on sand. In Proceedings of ASCE Geotechnical Engineering Congress, Boulder, Colo., 1-12 June 1991. GSP 27. Edited by F.G. McLean, D.A. Campbell, and D.W. Harris. American Society for Civil Engineers, New York. pp.788-802.

Towhata, I., Kawasaki, Y., Harada, N., and Sunaga, M. 1994. Contraction of soil subjected to traffic-type stress application. In Proceedings of the International Symposium on PreFailure Deformation Characteristics of Geomaterials, Sapporo, Japan, 12-14 September 1994. Edited by S. Shibuya, T. Mitachi, and S. Miura. A.A.Balkema, Rotterdam, the Netherlands. pp. 305-310.

Wong, R.K.S., and Arthur, J.R.F. 1985. Induced and inherent anisotropy in sand. Géotechnique, 
35(4): 471-481.

Yu, H.S. 2005. Three dimensional analytical solutions for shakedown of cohesive-frictional materials under moving surface loads. In Proceedings of the Royal Society Series A, 461(2059): pp.1951-1964. 


\section{LIST OF FIGURE AND TABLE CAPTIONS}

Table 1. Experimental conditions performed in this study

Figure 1. Ballasted track structure

Figure 2. Grain size distribution curves and physical properties

Figure 3. Moving-wheel loading test

Figure 4. Loading pattern of moving wheel loads

Figure 5. Single-point loading test

Figure 6. Multi-ring shear apparatus

Figure 7. Definition of stress and deformation

Figure 8. Loading conditions of multi-ring shear test adopting moving-wheel loading mode (a: axial stress, b: shear stress)

Figure 9. Rail seat forces - wheel position relationship

Figure 10. Rail seat force - vertical displacement relationships in moving-wheel loading tests of small scale model ballasted track (a: 1/5A ballast, b: 1/5B ballast)

Figure 11. Vertical displacement during cyclic loading in moving-wheel loading tests of small scale model ballasted track

Figure 12. Vertical load - vertical displacement relationships in single-point loading tests of small scale model ballasted track (a: 1/5A ballast, b: 1/5B ballast)

Figure 13. Vertical displacement during cyclic loading in single-point loading tests of small scale model ballasted track

Figure 14. Comparison of settlement characteristics (a: small scale model test, b: multi-ring shear test)

Figure 15. Deformation of glass beads $(D=5 \mathrm{~mm})$ in multi-ring shear test 
Figure 16. Effect of friction between specimen and rings in multi-ring shear apparatus

Figure 17. $\tau_{\mathrm{a} \theta-} \gamma_{\mathrm{a} \theta}$ relationships in cyclic loading multi-ring shear test

Figure 18. Comparison of stress-strain relationships between multi-ring shear test and hollow cylinder torsional shear test

Figure 19. Comparison of angle of shear resistance between multi-ring shear test and hollow cylinder torsional shear test

Figure 20. Axial stress - vertical displacement relationships in multi-ring shear tests (a: movingwheel loading mode, b: single-point loading mode)

Figure 21. Vertical displacement during cyclic loading in multi-ring shear tests (a: moving-wheel loading mode, b: single-point loading mode)

Figure 22. Stresses on a ballast element under a moving wheel load (a: stress condition at position C when a loading wheel lies on position B, b: Mohr's stress circles under a moving wheel load at various positions)

Figure 23. Estimation of principal stress axis rotation in multi-ring shear test adopting movingwheel loading mode (a: rotation of principal stress axis during a loading cycle, b: effect of loading conditions, c: effect of coefficient of earth pressure at rest)

Figure 24. Change in ratio of axial strain due to cyclic loading

Figure 25. Change in average ratio of axial strain due to the difference in loading condition 
Table 1. Experimental conditions performed in this study

\begin{tabular}{|c|c|c|c|c|c|c|}
\hline Test Name & Loading method & Vertical load $P / P_{\mathrm{r}}{ }^{*}$ & Axial stress $\left(\sigma_{\mathrm{a}}\right)_{\max }$ & Shear stress $\left(\tau_{\mathrm{a} \theta}\right)_{\max }$ & $\rho_{\mathrm{d} 0}$ for $1 / 5 \mathrm{~A}$ ballast & $\rho_{\mathrm{d} 0}$ for $1 / 5 \mathrm{~B}$ ballast \\
\hline & & $(\mathrm{kN})$ & $(\mathrm{kPa})$ & $(\mathrm{kPa})$ & $\left(\mathrm{g} / \mathrm{cm}^{3}\right)$ & $\left(\mathrm{g} / \mathrm{cm}^{3}\right)$ \\
\hline Small scale model & Moving-wheel loading & 4.0 & --- & --- & 1.43 & 1.48 \\
\hline Small scale model & Single-point loading & 2.0 & --- & --- & 1.40 & 1.46 \\
\hline Multi-ring shear test & Monotonic loading & --- & 156.8 & maximum & 1.42 & 1.48 \\
\hline Multi-ring shear test & Moving-wheel loading & 2.0 & 80.0 & 12.8 & 1.42 & 1.48 \\
\hline Multi-ring shear test & Moving-wheel loading & 4.0 & 155.6 & 25.5 & 1.42 & 1.48 \\
\hline Multi-ring shear test & Moving-wheel loading & 6.0 & 231.1 & 38.3 & 1.43 & 1.47 \\
\hline Multi-ring shear test & Moving-wheel loading & --- & 80.0 & 25.5 & 1.42 & --- \\
\hline Multi-ring shear test & Moving-wheel loading & --- & 80.0 & 38.3 & 1.43 & --- \\
\hline Multi-ring shear test & Moving-wheel loading & --- & 155.6 & 12.8 & 1.42 & 1.48 \\
\hline Multi-ring shear test & Moving-wheel loading & --- & 155.6 & 38.3 & 1.42 & 1.48 \\
\hline Multi-ring shear test & Moving-wheel loading & --- & 231.1 & 12.8 & 1.43 & --- \\
\hline Multi-ring shear test & Moving-wheel loading & -- & 231.1 & 25.5 & 1.42 & --- \\
\hline Multi-ring shear test & Single-point loading & 2.0 & 80.0 & 0 & 1.43 & 1.48 \\
\hline Multi-ring shear test & Single-point loading & 4.0 & 155.6 & 0 & 1.43 & 1.48 \\
\hline Multi-ring shear test & Single-point loading & 6.0 & 231.1 & 0 & 1.43 & 1.48 \\
\hline
\end{tabular}

$* P$ at moving-wheel loading; $P_{\mathrm{r}}$ at single-point loading 


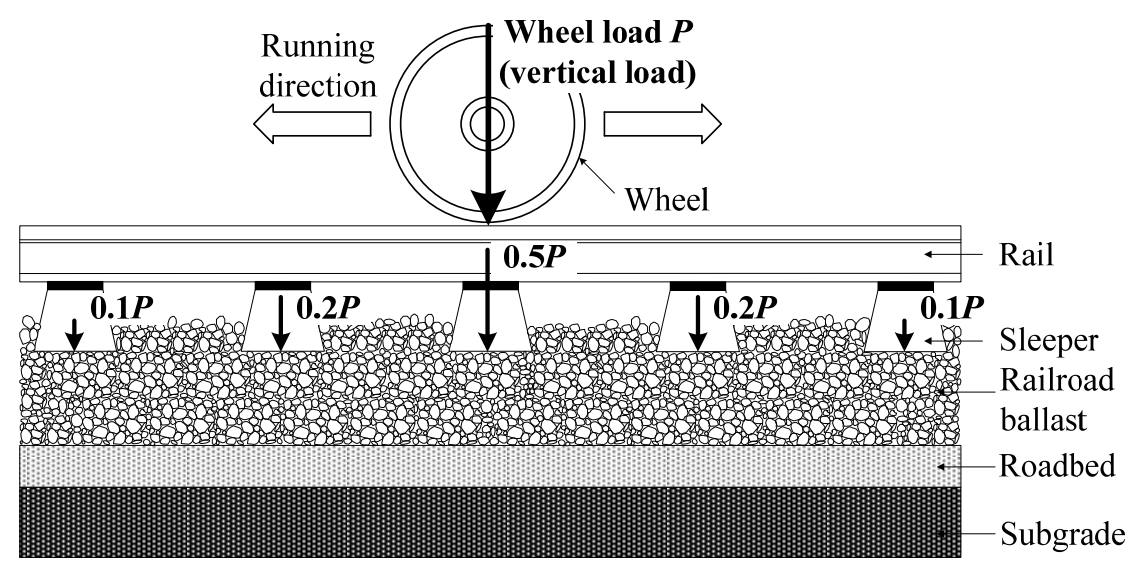

Figure 1. Ballasted track structure

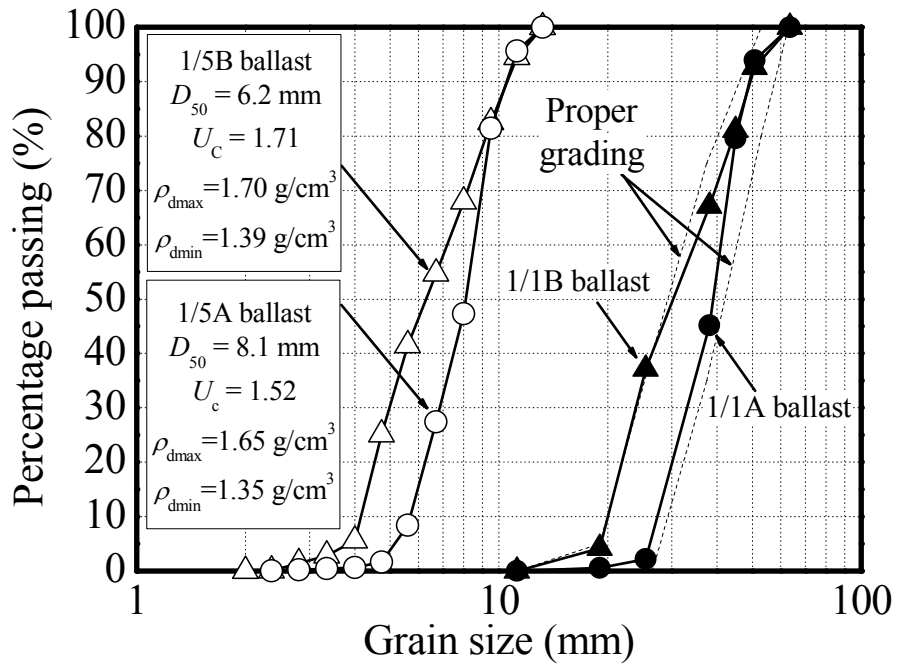

Figure 2. Grain-size distribution curves and physical properties

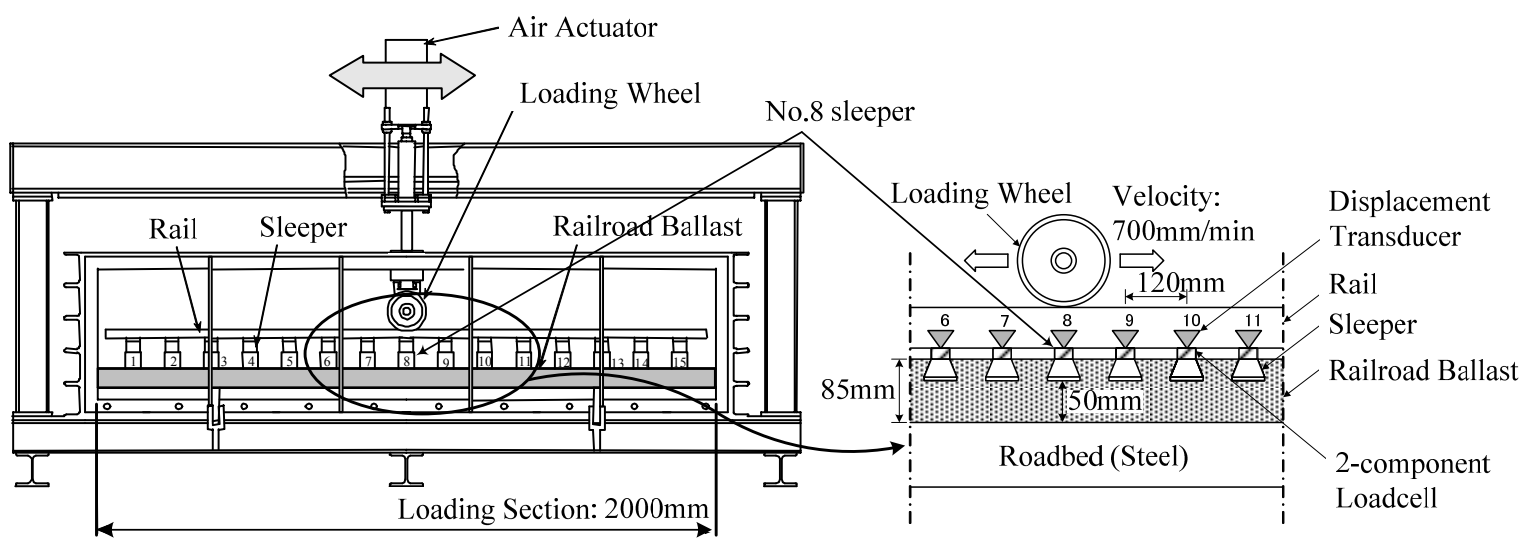

Figure 3. Moving-wheel loading test 


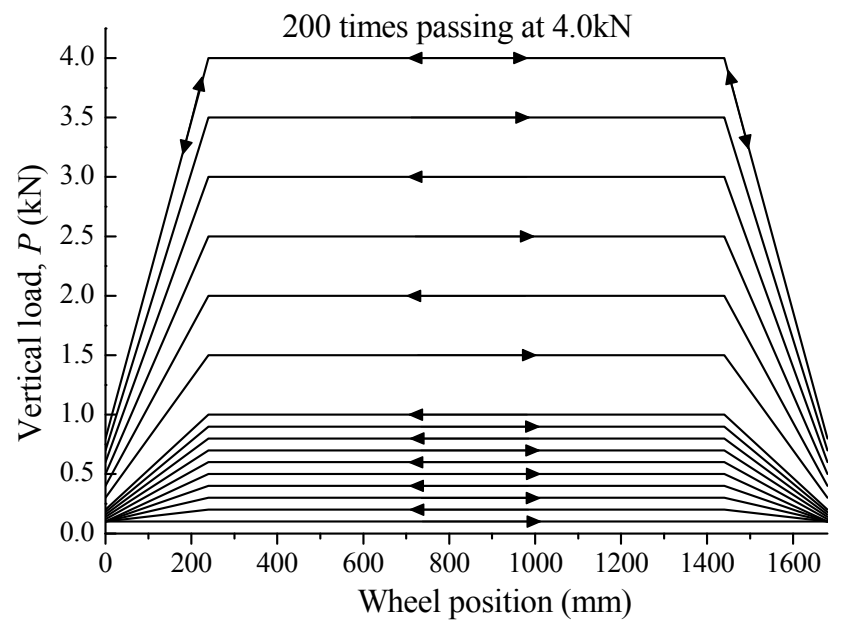

Figure 4. Loading pattern of moving wheel loads

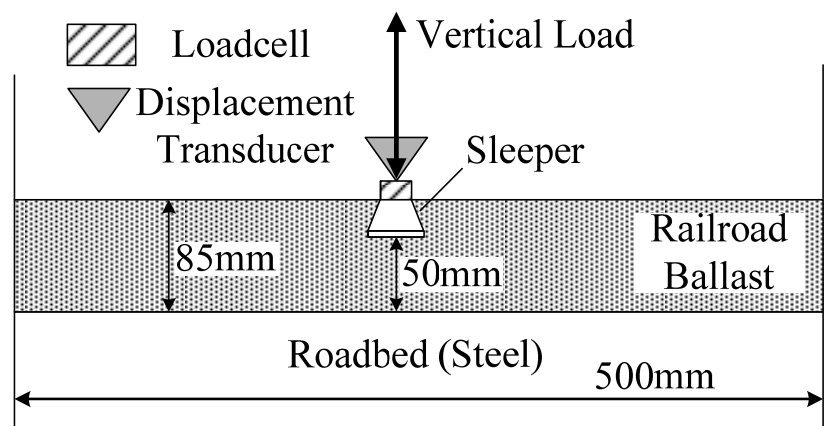

Figure 5. Single-point loading test

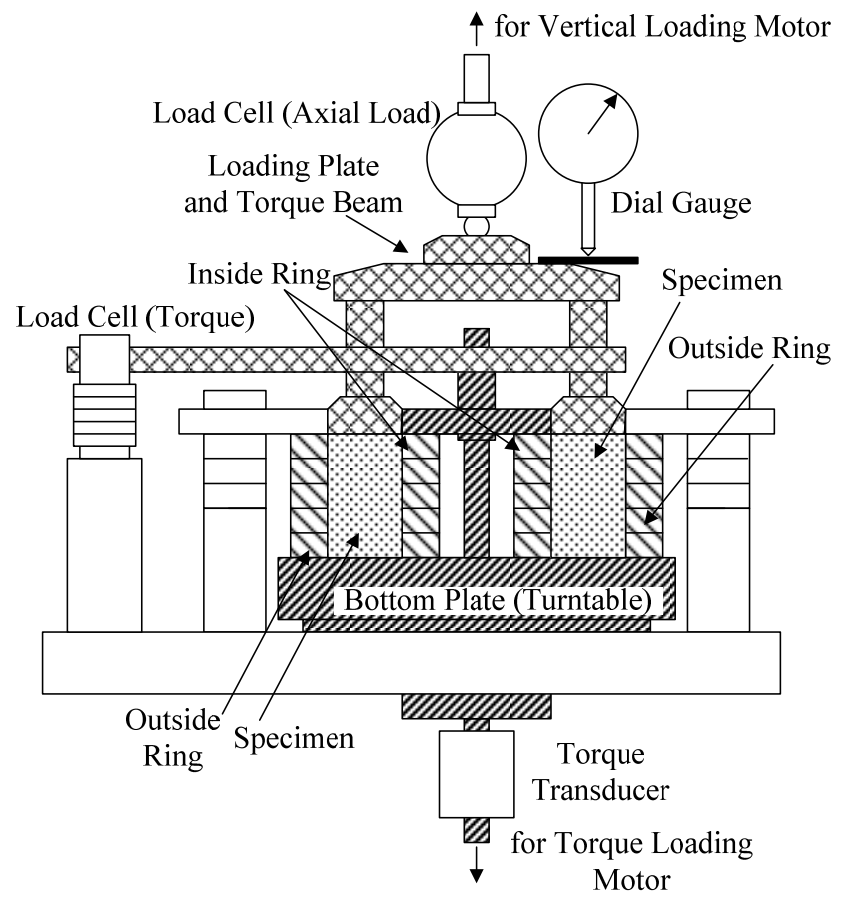

Figure 6. Multi-ring shear apparatus 


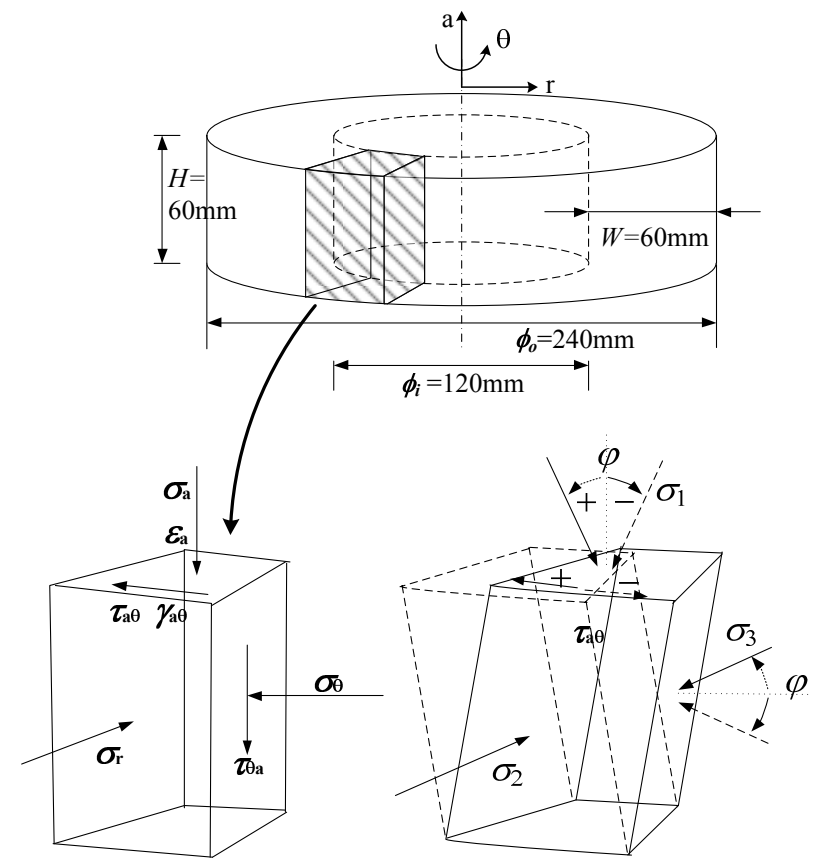

Figure 7. Definition of stress and deformation. $\varphi$, rotational angle of principal stress (major, $\sigma_{1}$; intermediate, $\sigma_{2}$; minor, $\sigma_{3}$ ); subscript $o$ of $\varphi$ refers to the outside diameter and subscript $i$ refers to the inside diameter.
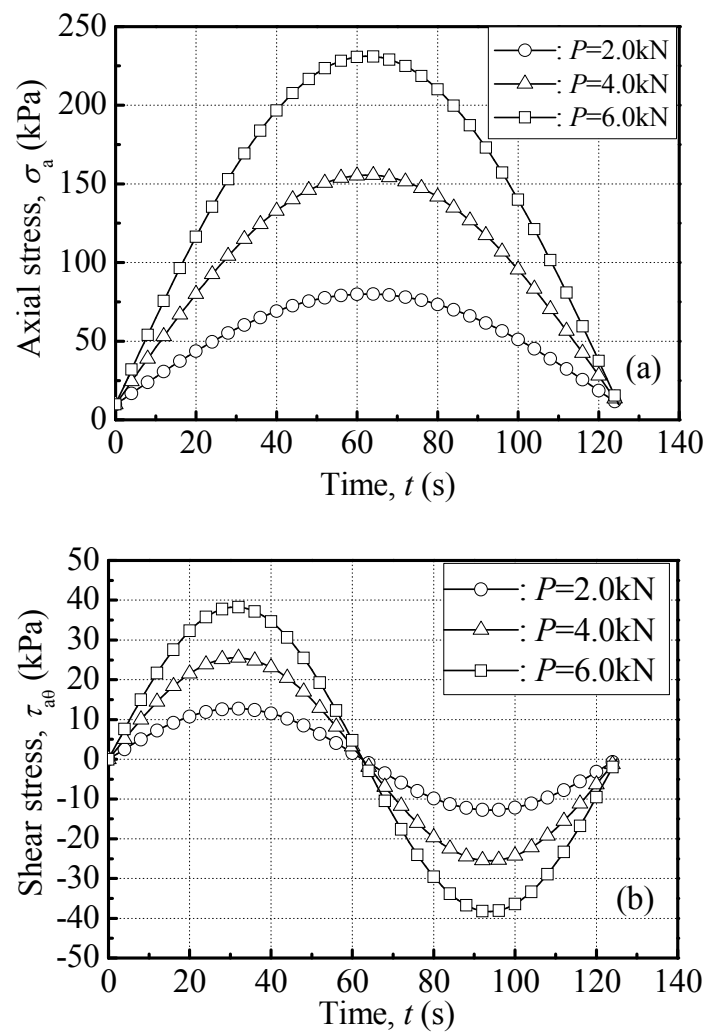

Figure 8. Loading conditions of multi-ring shear test using moving-wheel loading mode: (a) axial stress; (b) shear stress. 


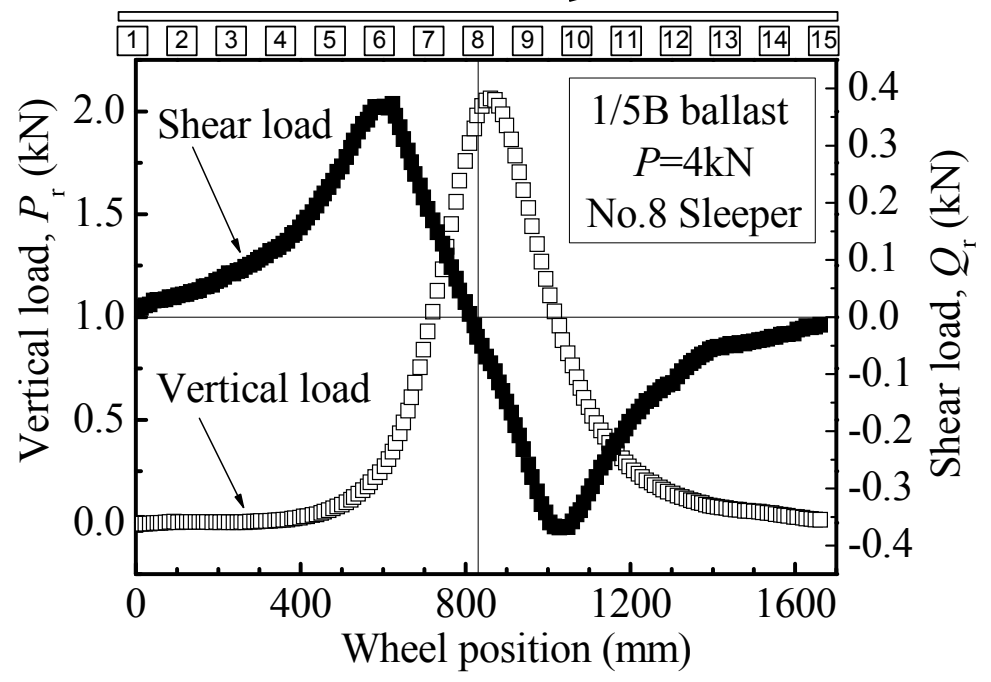

Figure 9. Rail seat forces - wheel position relationship
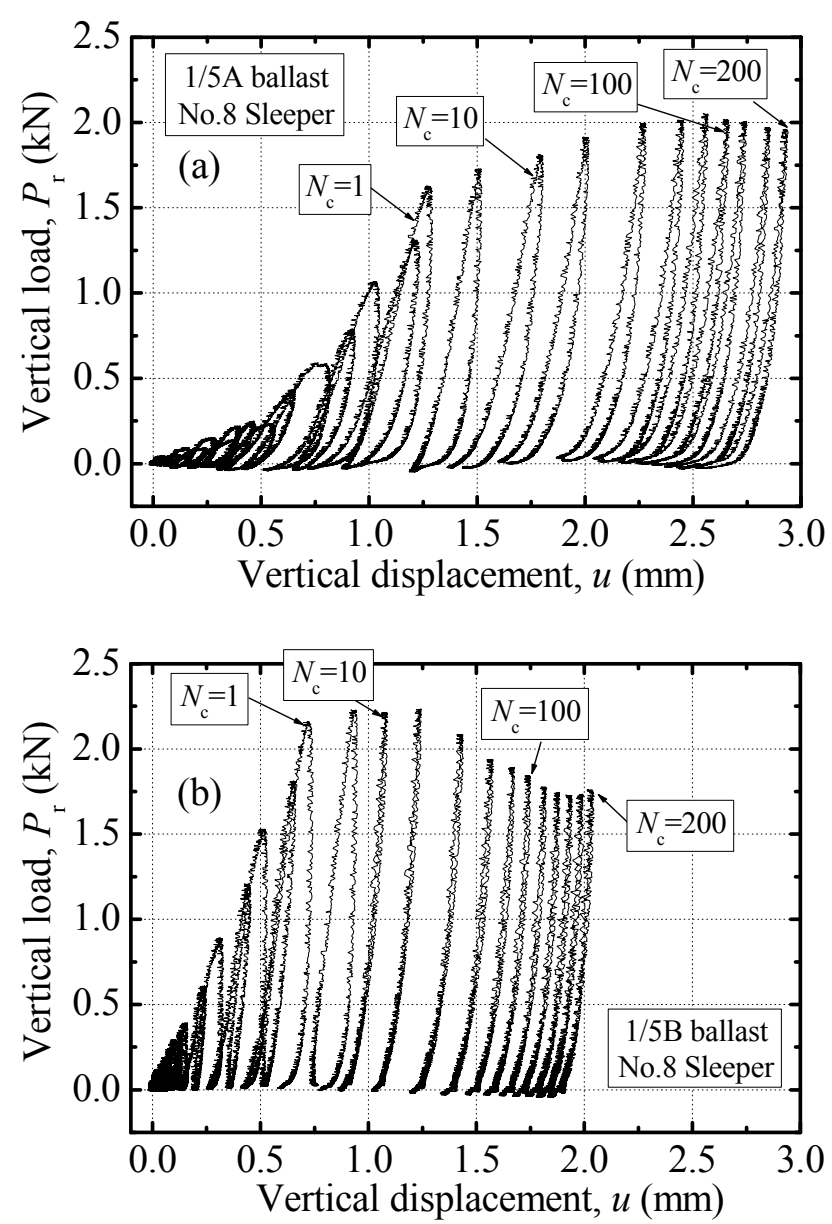

Figure 10. Rail seat force - vertical displacement relationships in moving-wheel loading tests of small scale-model ballasted track: (a) 1/5A ballast; (b) 1/5B ballast. 


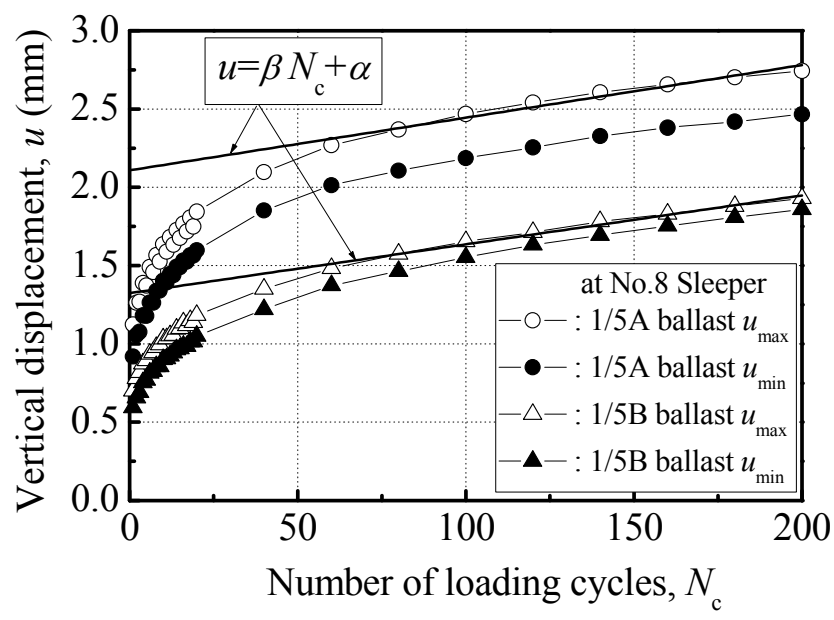

Figure 11. Vertical displacement during cyclic loading in moving-wheel loading tests of small scale-model ballasted track. $\alpha$, initial settlement; $\beta$, rate of progressive settlement.
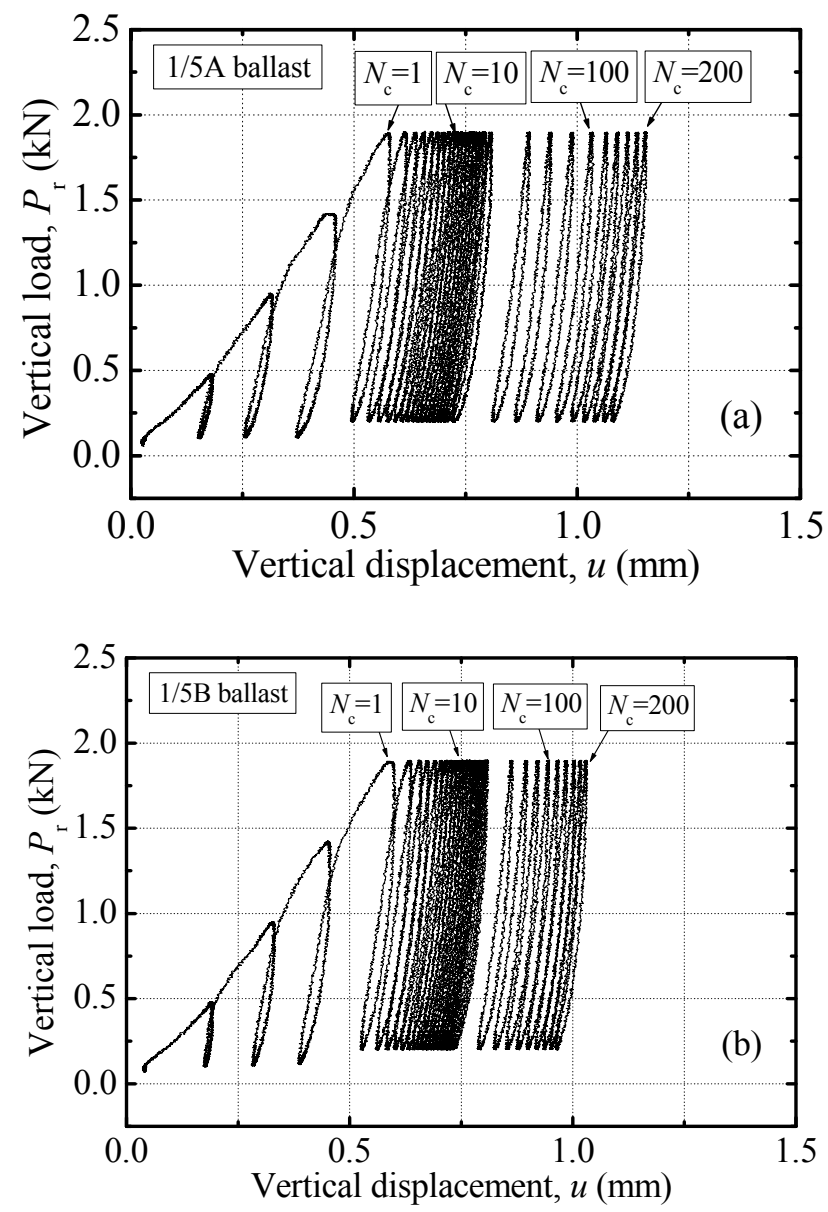

Figure 12. Vertical load - vertical displacement relationships in single-point loading tests of small-scale model ballasted track: (a) 1/5A ballast; (b) 1/5B ballast. 


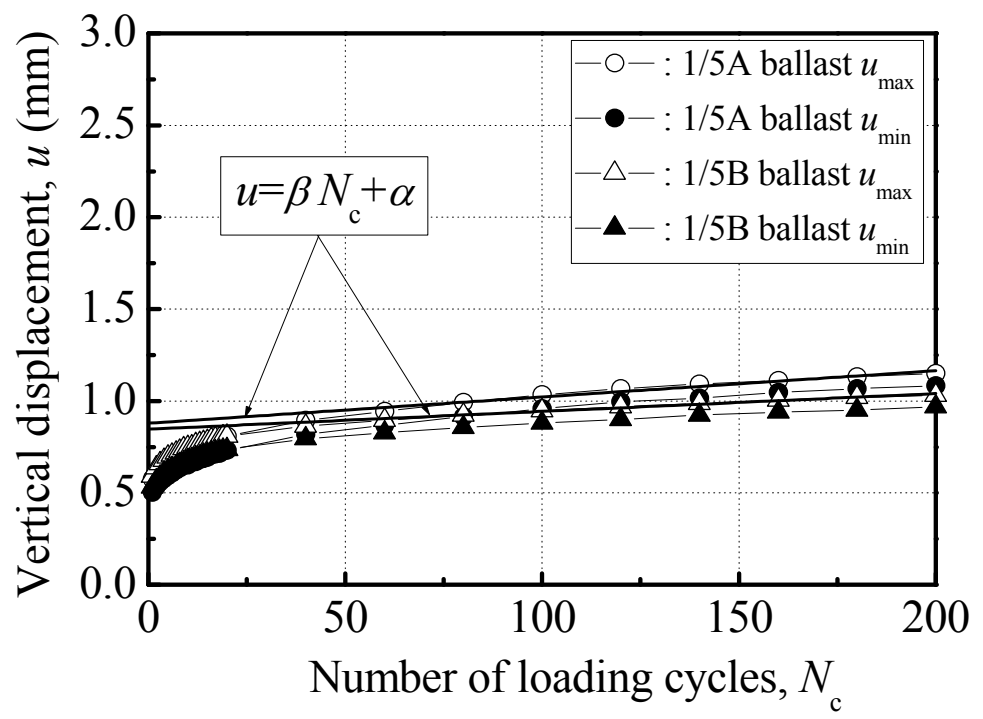

Figure 13. Vertical displacement during cyclic loading in single-point loading tests of small scale-model ballasted track
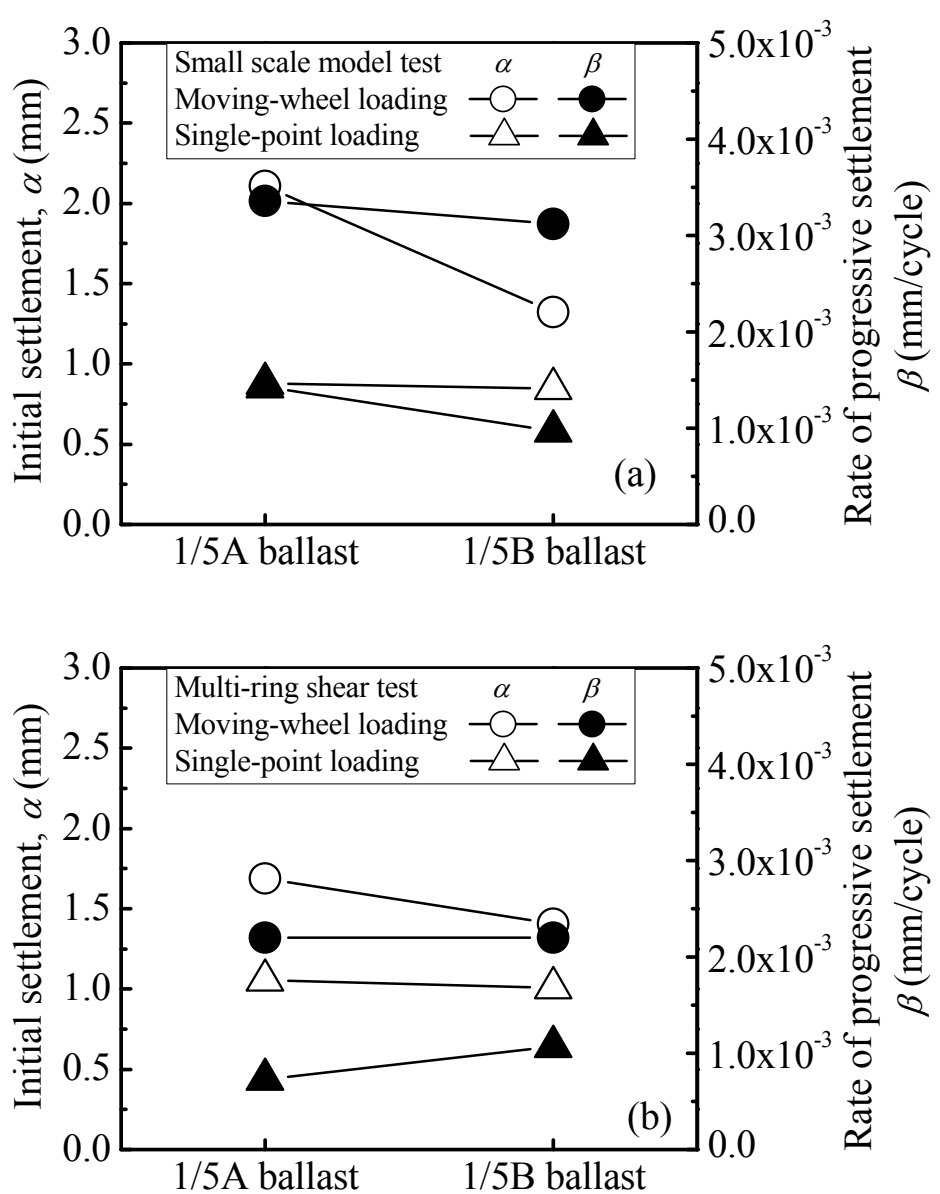

Figure 14. Comparison of settlement characteristics: (a) small-scale model test; (b) multi-ring shear test. 


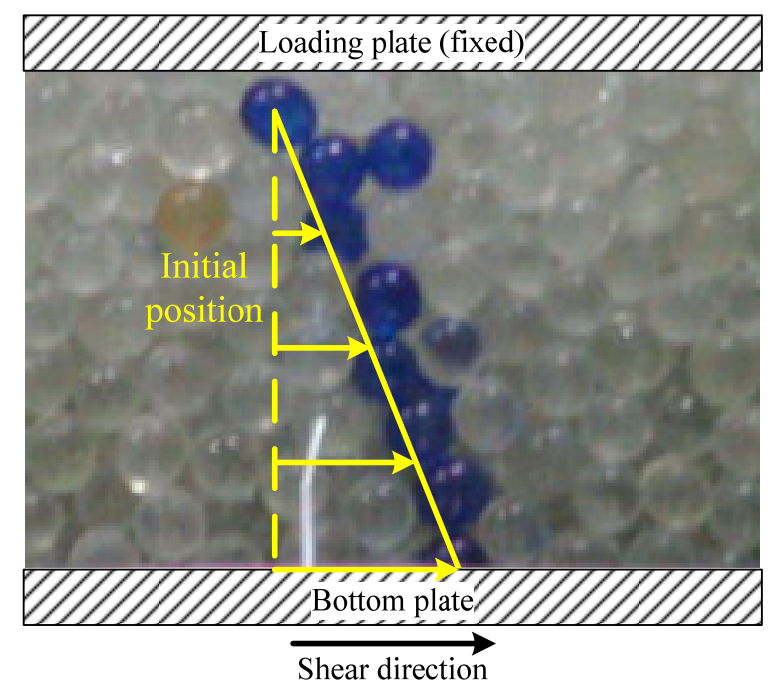

Figure 15. Deformation of glass beads $(D=5 \mathrm{~mm})$ in multi-ring shear test

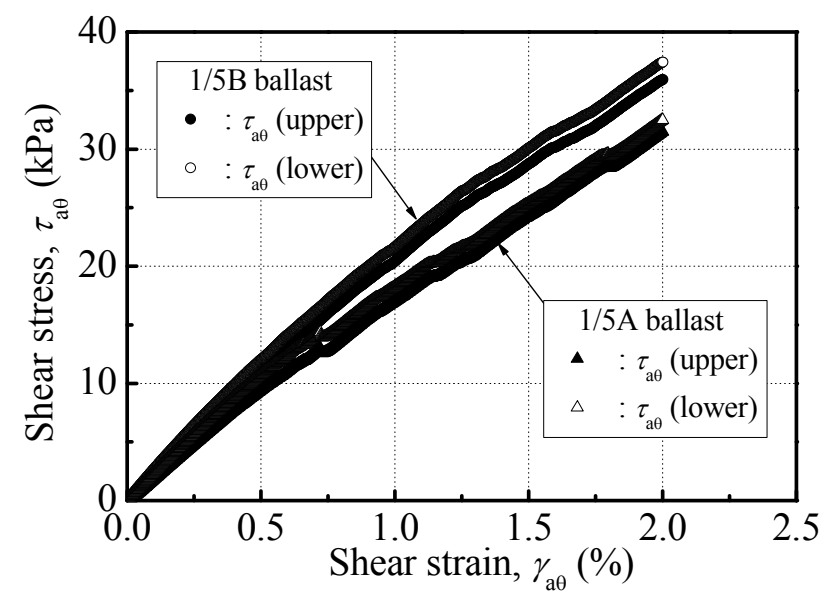

Figure 16. Effect of friction between specimen and rings in multi-ring shear apparatus

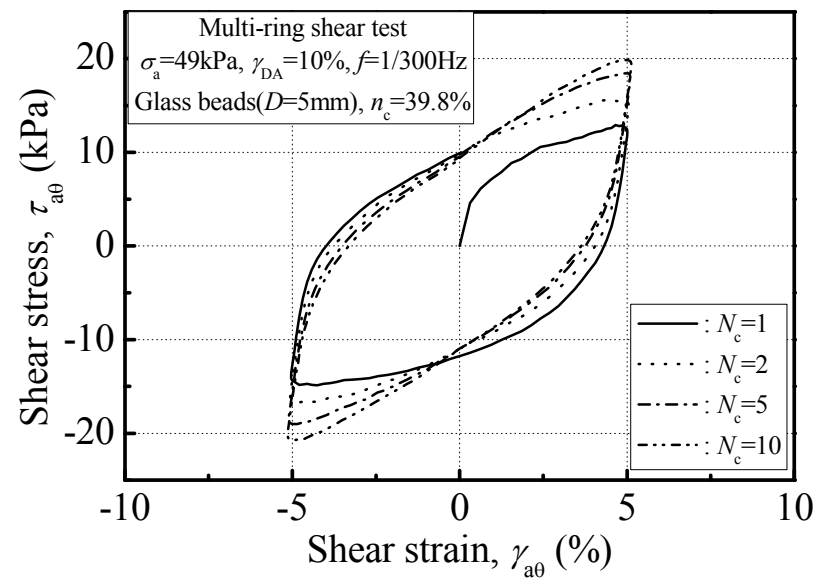

Figure 17. $\tau_{\mathrm{a} \theta-\gamma_{\mathrm{a} \theta}}$ relationships in cyclic loading multi-ring shear test. $n_{\mathrm{c}}$, porosity after consolidation; $\gamma_{\mathrm{DA}}$, double amplitude of shear strain. 


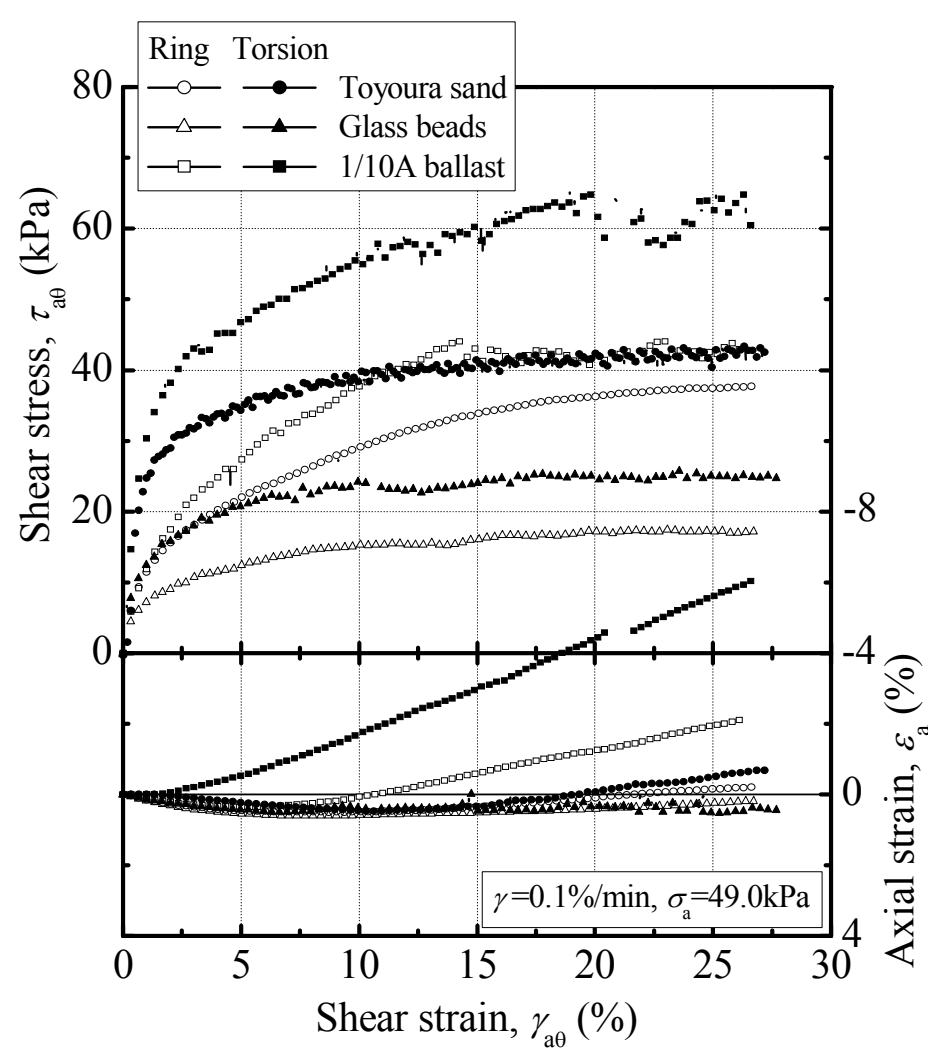

Figure 18. Comparison of stress-strain relationships between multi-ring shear test and hollow cylinder torsional shear test

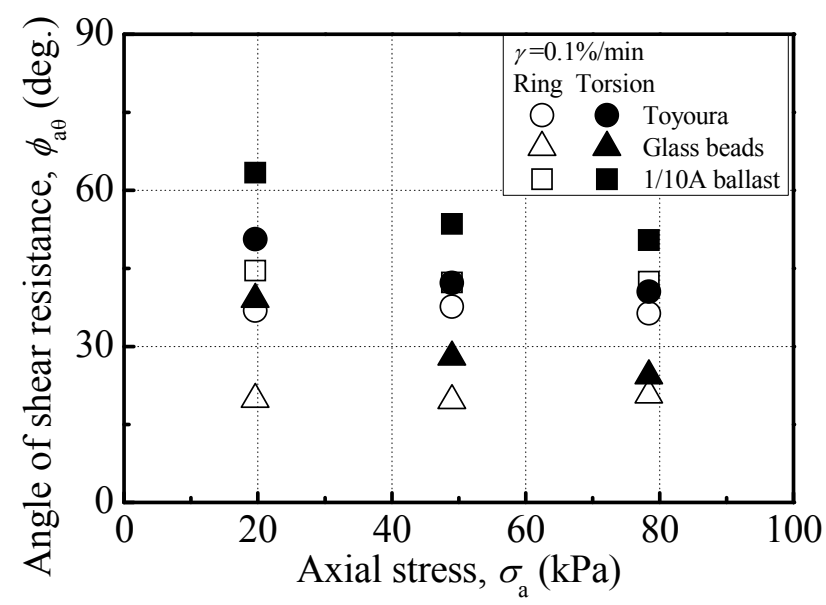

Figure 19. Comparison of angle of shear resistance between multi-ring shear test and hollow cylinder torsional shear test 

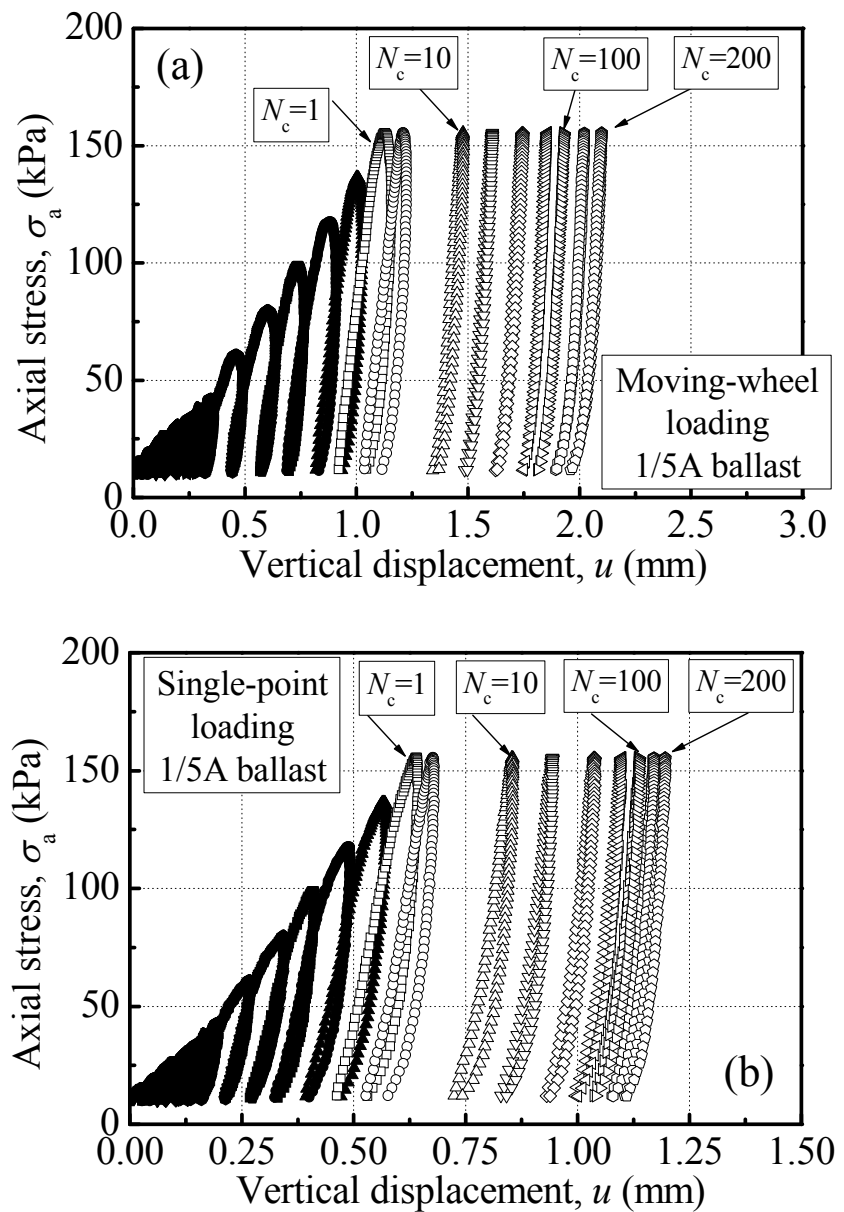

Figure 20. Axial stress - vertical displacement relationships in multi-ring shear tests: (a) moving-wheel loading mode; (b) single-point loading mode. 

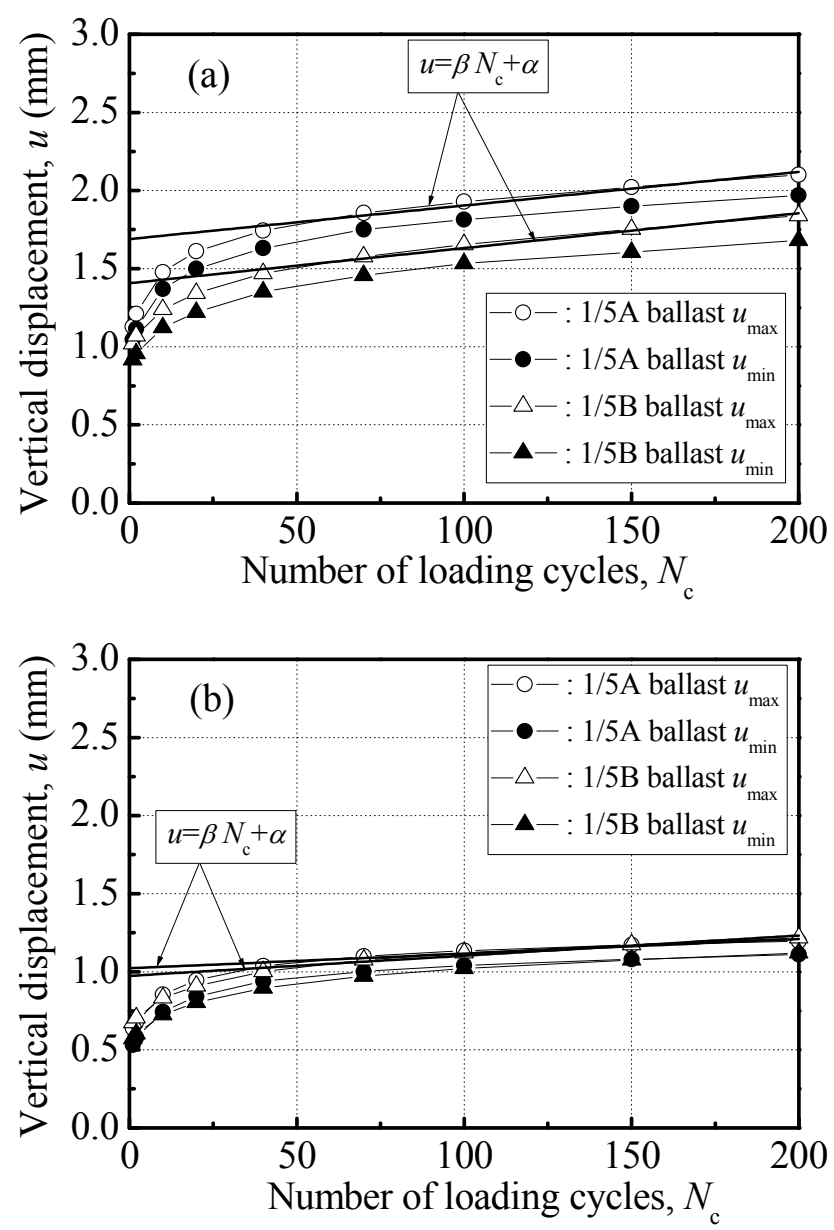

Figure 21. Vertical displacement during cyclic loading in multi-ring shear tests: (a) moving-wheel loading mode; (b) single-point loading mode. 

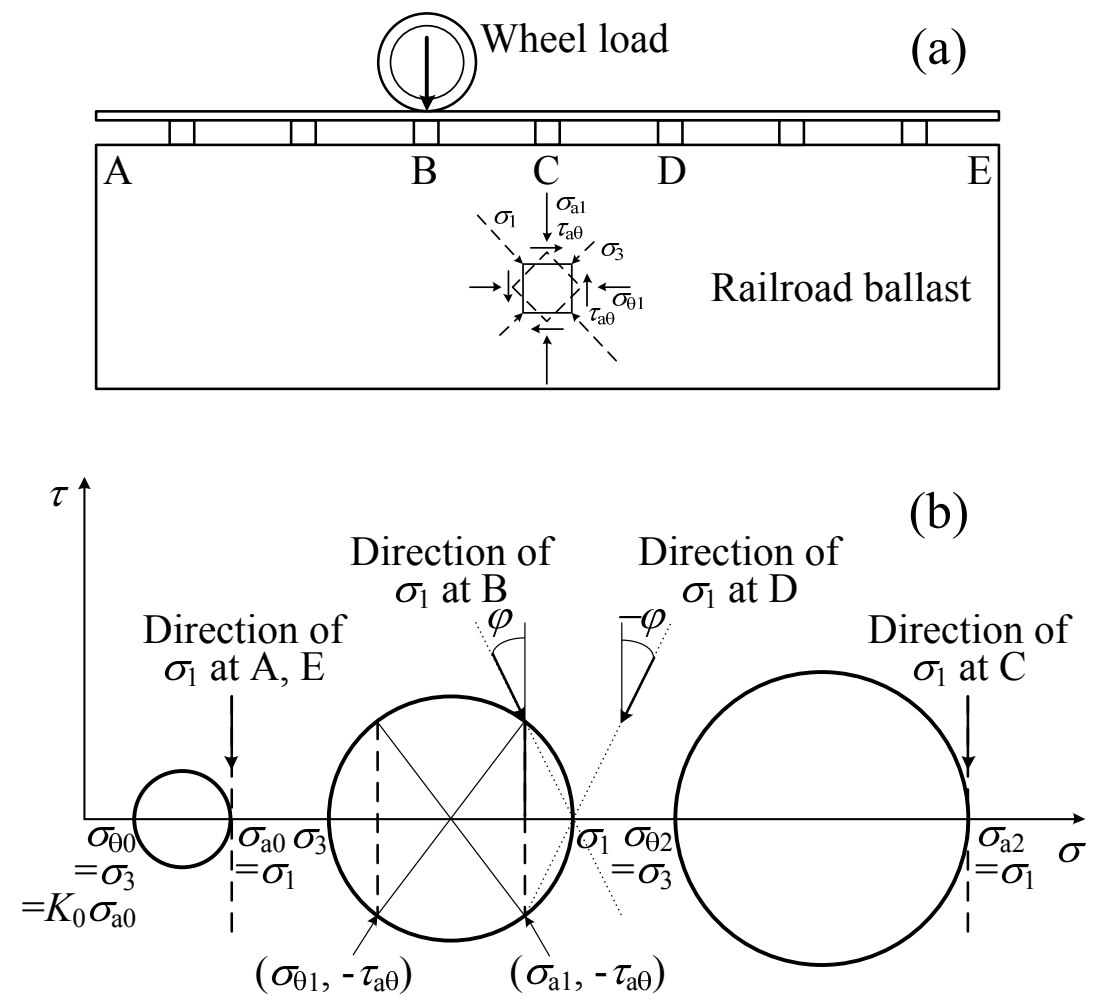

Figure 22. Stresses on a ballast element under a moving-wheel load: (a) stress condition at position C when a loading wheel lies on position B; (b) Mohr's stress circles under a moving-wheel load at various positions. 

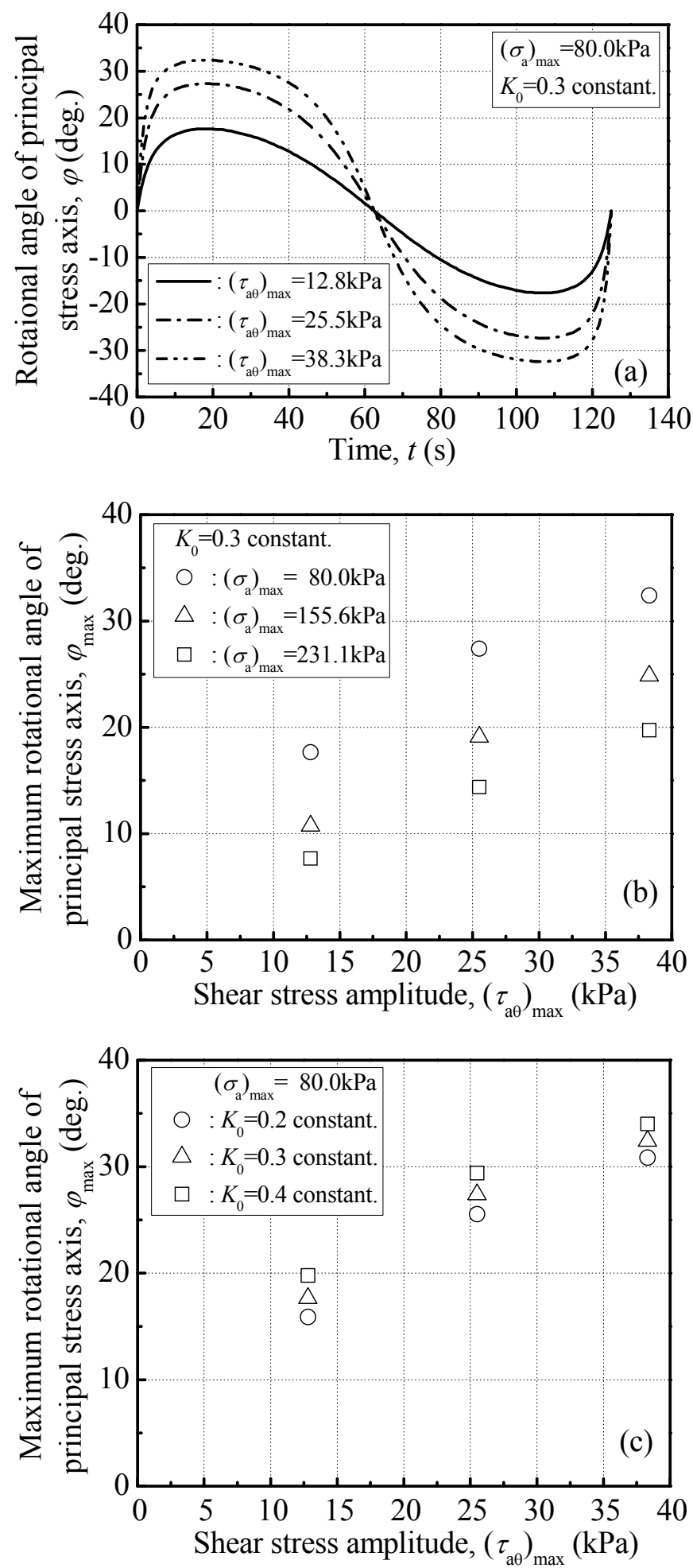

Figure 23. Estimation of principal stress axis rotation in multi-ring shear test using moving-wheel loading mode: (a) rotation of principal stress axis during a loading cycle; (b) effect of loading conditions; (c) effect of coefficient of earth pressure at rest. 


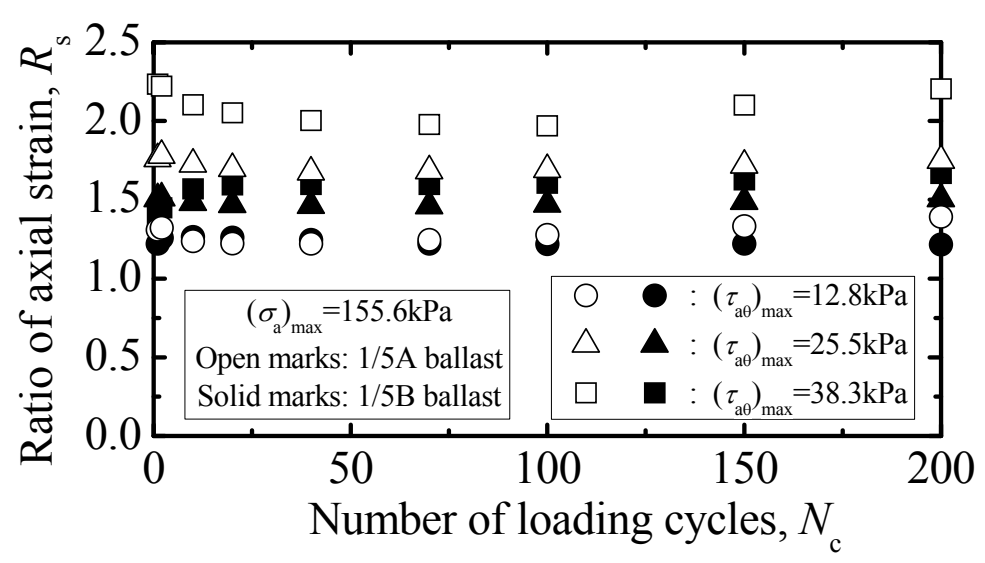

Figure 24. Change in ratio of axial strain due to cyclic loading

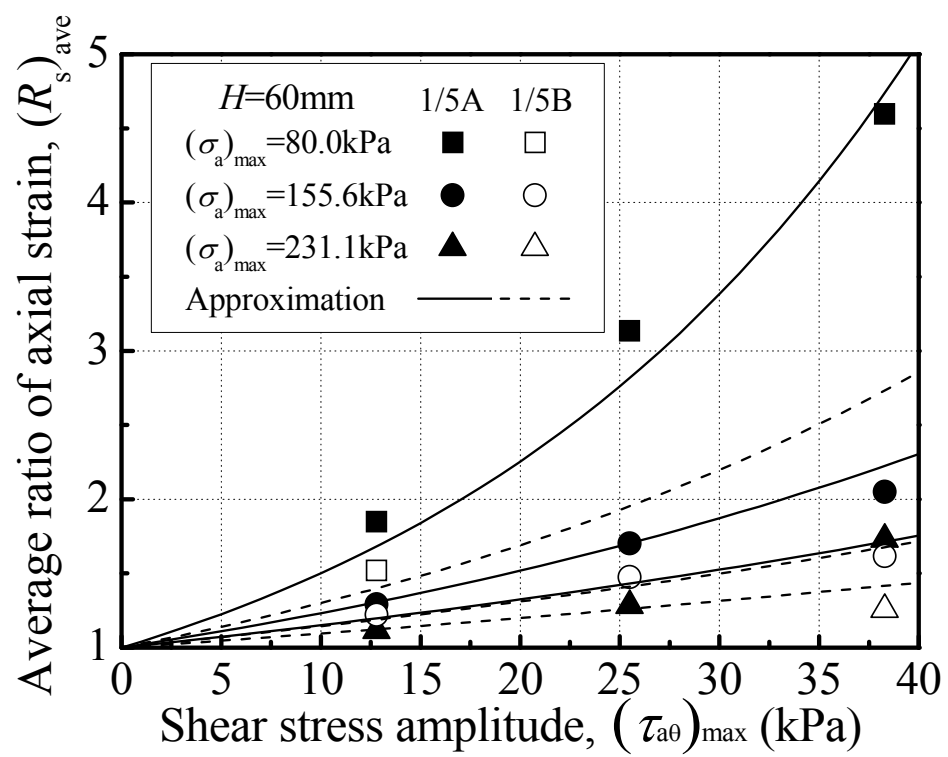

Figure 25. Change in average ratio of axial strain due to the difference in loading condition 